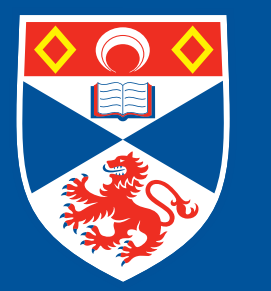

University of

St Andrews

Spatial Takeoff in the First

I Industrial Revolution

$+$

$r$

D

Alex Trew $\stackrel{\mapsto}{\mathfrak{r}}$

$\nabla$

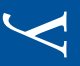

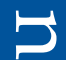

Q

$\xi$

ค

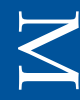

0

S

$r$

0

(D)

$\Omega$

0

"

0

३

$\mapsto$.

ค

$D$

ט

$\stackrel{\leftrightarrow}{\longleftarrow}$

es

m.

$\omega$
CDMA Working Paper Series No. 1401

1 Jan 2014 (revised 1 Jan 2014)

JEL Classification: O11, O18, O33, N13, N93, R12.

Keywords: Endogenous growth, first industrial revolution, economic geography, structural change. 


\title{
Spatial Takeoff in the First Industrial Revolution*
}

\author{
Alex Trew ${ }^{\dagger}$ \\ University of St. Andrews
}

1 January 2014

\begin{abstract}
Using the framework of Desmet and Rossi-Hansberg (forthcoming), we present a model of spatial takeoff that is calibrated using spatially-disaggregated occupational data for England in c.1710. The model predicts changes in the spatial distribution of agricultural and manufacturing employment which match data for c.1817 and 1861. The model also matches a number of aggregate changes that characterise the first industrial revolution. Using counterfactual geographical distributions, we show that the initial concentration of productivity can matter for whether and when an industrial takeoff occurs. Subsidies to innovation in either sector can bring forward the date of takeoff while subsidies to the use of land by manufacturing firms can significantly delay a takeoff because it decreases spatial concentration of activity.
\end{abstract}

JEL Classifications: O11; O18; O33; N13; N93; R12.

Keywords: Endogenous growth, first industrial revolution, economic geography, structural change.

${ }^{*}$ This paper has benefited enormously from the comments of an Editor and two anonymous referees. I am grateful to Esteban Rossi-Hansberg for providing MATLAB code and to Leigh Shaw-Taylor for his permission to work with the data produced by the Cambridge Group; Peter Kitson constructed a comparison database and Max Satchell provided the GIS files. I am also grateful for discussion to Stephan Heblich, Charles Nolan, Gary Shea and conference participants at St. Andrews and at the Urban Economics Association meeting in Ottawa.

†School of Economics and Finance, University of St. Andrews, St. Andrews, Fife, UK, KY16 9AJ. Tel: +44(0)1334 461950. Email: alex.trew@st-andrews.ac.uk. Web: www.standrews.ac.uk/ awt2. 


\section{Introduction}

Economic takeoff is often a starkly geographical phenomenon with leading industries that are highly spatially concentrated and different regions that are affected in different ways. Such spatial heterogeneities are not, however, generally a part of the models we use to understand the timing and speed of transition from slow-growing agricultural economies to fast-growing industrial ones. As a result, we lack a framework for studying the dynamic effects of policies that are bound up in geography, such as subsidies for industrial hubs or expenditure on infrastructural development. This is partly because of analytical difficulties to do with modelling geography, but it is also because of a lack of sufficiently disaggregated data on the nature of spatial development through an entire period of takeoff. Using new data that captures the spatially-disaggregated nature of the industrial revolution in England, this paper builds on recent advances in modelling spatial development to construct a model of spatial takeoff.

Just how significant are geographical heterogeneities? Data for modern economies point to the importance of geography to the characterisation of aggregate growth, growth in cities and in sub-national regions (see, for example, Henderson et al., 2011). Historical data permit us to consider spatial development during a broader structural transformation, however. Using occupational data from parish-level records, the groundbreaking work of Shaw-Taylor et al. (2010b) and the wider project described therein shows that early industrial England was characterised by concentrated geographical 'hotspots' of population growth in areas that were predominantly manufacturing based. ${ }^{1}$ That data quantifies a number of spatially-heterogenous features of the first industrial revolution, such as the deindustrialisation of the South of England during the eighteenth century.

Using the framework of Desmet and Rossi-Hansberg (forthcoming), this paper introduces non-homothetic preferences into a dynamic model of endogenous innovation in two sectors - agriculture and manufacturing - where

\footnotetext{
${ }^{1}$ To see this visually, see, e.g., Figure 4 'Population densities at quasi-parish level for England and Wales c.1670 and 1800-1891' on the project website: http://www.geog.cam.ac.uk/research/projects/occupations/englandwales1379-1911/.
} 
trade across a continuum of space is costly and where land is competed for as a factor of production. Agglomeration and transport costs matter for the locations of activity and the endogenous rate of technological progress in each sector. Innovation is subject to a fixed cost and so investment in innovation occurs when firms are large enough to amortize that cost over a sufficient quantity of output. Since the manufacturing innovations that underpinned the industrial revolution were energy-intensive, we make the assumption that the fixed cost to innovating in the manufacturing sector is proportional to the local energy costs. Those costs reflect both the location of natural resources (coal) and the (non-uniform) costs of transporting it. The framework is tractable enough for the model to be parameterised and for equilibrium outcomes to be studied quantitatively. The most novel item we calibrate is the initial spatial distribution of productivity in each sector. In particular, we use new data in Shaw-Taylor et al. (2010b) to estimate the geographical distribution of employment for c.1710 and use that to calibrate the initial distribution of productivity. We then compare the spatial predictions of the model against the data for c.1817 and 1861 from Shaw-Taylor et al. (2010b).

The model matches a number of the aggregate and geographically heterogenous aspects of the first industrial revolution over the period 1710-1860. Initial innovation in agricultural production is concentrated in the South, around the population of London (cf. Allen, 2004). That slowly increases demand for the consumption of manufactured goods and leads to the emergence of manufacturing firms in the North with an associated migration of labor to work there. Once those firms reach a sufficient scale, manufacturing innovation begins endogenously. The takeoff in per capita growth proceeds at a time and place that matches the data. The ability to capture the structural change that results from agricultural innovation is much like in Desmet and Parente (2012). We establish, however, that the spatially heterogenous nature of the economy was critical to whether and when an industrial takeoff occurs by simulating the model with a series of counterfactual geographical environments. We also look at the role of policy: Subsidies to manufacturing innovation bring forward the date of industrial takeoff and locate it closer to the source of cheap energy. In contrast, a subsidy to the use of land by 
manufacturing firms can significantly delay takeoff because it lowers the spatial concentration of manufacturing firms. We also find a significant role for international trade in explaining the timing of takeoff.

The rest of the paper is organised as follows: Section 2 reports evidence on the industrial takeoff in England and connects that to some extant models of takeoff. Section 3 introduces the model of spatial takeoff, which is based on Desmet and Rossi-Hansberg (forthcoming). The model is parameterised in Section 4 with equilibrium outcomes compared against the record for the first industrial revolution in Section 5. Section 6 considers a number of counterfactual initial distributions for manufacturing productivity. Section 7 considers the impact of including international trade and Section 8 looks at a number of policy interventions. Section 9 offers some concluding remarks.

\section{The First Industrial Revolution}

It is worth going over the macroeconomic facts of the industrial revolution before turning to its spatially-heterogenous characteristics. The industrial revolution may be characterised by an aggregate shift of employment and incomes from agricultural to industrial activities along with a sustained increase in per capita output growth. We focus mainly on these two characteristics, though the quantitative modelling exercise in Section 5 will look to fit additional historical data for relative prices, wages and land rents.

\subsection{Per Capita Growth and Employment Shares}

The revisionist ${ }^{2}$ view of per capita growth during the first industrial revolution, summarised in Crafts and Harley (1992) and reported in Table 1, has established that growth in the eighteenth century was more muted than once thought: A significant increase in aggregate growth was not observed until the second quarter of the nineteenth century. The Crafts-Harley view in turn

\footnotetext{
${ }^{2}$ Cf. Deane and Cole (1967); the revisionist view is now generally accepted (see Mokyr, 2004) and has been confirmed under different methodologies (e.g., Antràs and Voth, 2003). An alternative perspective, which suggests somewhat higher growth in the early eighteenth century, is presented in Clark (2007).
} 
implies that England was far wealthier than once thought as far back as the early 18th Century and that the macro-inventions of the eighteenth century took a long time to make an impact upon aggregate per capita growth.

Table 1: Estimates of percentage growth of per capita real output in Britain

\begin{tabular}{c|cccc}
\hline & $1700-60$ & $1760-1800$ & $1800-30$ & $1830-70$ \\
\hline Crafts and Harley (1992) & 0.3 & 0.17 & 0.52 & 1.98 \\
\hline \hline
\end{tabular}

From Mokyr (2004)

The best estimates we have for employment shares during the period are from Shaw-Taylor et al. (2010b) which is based on occupational records from 1,000 baptismal registers for c.1710 and over 10,000 registers for subsequent years. ${ }^{3}$ Table 2 reports estimates for male employment shares according to the primary-secondary-tertiary (PST) classification system described in Wrigley (2010b). ${ }^{4}$ The substantial proportion of labor in the secondary sector during the eighteenth century, increasing by only eight percentage points over 160 years, is striking.

Table 2: Estimates of male employment shares in England

\begin{tabular}{l|cccc}
\hline & c.1710 & 1817 & 1851 & 1871 \\
\hline labor in primary & $43.4 \%$ & $38.9 \%$ & $30.7 \%$ & $25.2 \%$ \\
labor in secondary & $38.7 \%$ & $42.2 \%$ & $45.3 \%$ & $46.8 \%$ \\
\hline \hline
\end{tabular}

From Shaw-Taylor, et al., (2010)

Combined with the relatively muted growth up until 1830, these data present a problem for models of growth where the labor shift is the industrial takeoff. Matsuyama (1992) relates industrial takeoff to the labor released by

\footnotetext{
${ }^{3}$ The earlier perspective on employment shares is that reported in Crafts (1994), which, for the eighteenth century, is based on a reworking of Lindert and Williamson (1982) that uses data from up to 50 parish registers. We focus on the newer data in Shaw-Taylor et al. (2010b) here. This data is provisional and subject to some revision, but this sample dwarfs the number of registers on which the Crafts (1994) data is based.

${ }^{4}$ The PST classification is based on the income elasticity of demand for each type of good: Primary sector goods (agriculture, mining, fishing) generally have income elasticity less than one; secondary (manufacturing, construction) more than one, but less than tertiary (services, transport). See Figure 2 in Shaw-Taylor et al. (2010b).
} 
increases in agricultural productivity while Gollin et al. (2002) parameterise a model in this spirit. The pace of transition is limited by the rate at which labor is released from agriculture. Other papers, such as Hayashi and Prescott (2008), emphasize early manufacturing innovation in raising wages, increasing incentives for labor to migrate out of agriculture. Yang and Zhu (2009) focus on the role of manufacturing innovation in modernising agricultural production, thus releasing labor and permitting industrial takeoff. From this perspective, the transition is a contemporaneous relationship between more labor in manufacturing and higher aggregate growth, a pattern not observed during the first industrial revolution.

Agricultural productivity did play a role, however, in advance of the wider industrial takeoff. Allen (2004) finds that agricultural output per worker doubled between 1600 and 1750. Enclosures of farms, increases in farm size and improvements in farming methods drove an agricultural revolution in advance of the industrial revolution. That there is little contemporaneous contribution of agricultural productivity improvements to the industrial takeoff is consistent with the evidence on the real wages of farm workers in Clark (2001). Agricultural innovation may have been enough to take employment shares to their early eighteenth century levels, but that was not sufficient to generate industrial takeoff alone.

We could start to understand these macroeconomic data in the context of an endogenous growth model where employment shares and agricultural innovations are only a part of the conditions necessary for the takeoff of industrial productivity. That an endogenous growth story is necessary fits with the recent thesis in Allen (2009) that the English advantage was in the high wages relative to low energy costs that created incentives to develop and implement the new labor-saving technologies which underpinned the takeoff in aggregate growth. There is evidence that the patterns of employment and innovation were not independent of geographical space, however. A proper accounting for endogenous innovation decisions through the industrial takeoff can thus incorporate an explicit role for geography. 


\subsection{Spatial Heterogeneities}

A number of studies, such as Cottrell (1980), Langton (1984) and Hudson (1989), have pointed out that beneath the aggregate changes that characterise the first industrial revolution are differences in the intensity and dynamics of economic activity across space. We can consider the spatial distribution of economic activity and the distribution of coal.

The advantage of the Shaw-Taylor et al. (2010b) data is the ability to disaggregate geographically the employment shares and their changes over time. In Section 4 we use this data to calibrate the initial productivity levels in the model and to compare simulation output against the record. Here, a few key findings of Shaw-Taylor et al. can be summarised. First, the industrial economic geography of England was already established by the mid-eighteenth century. That economic geography was characterised by 'hotspots' of activity and high population growth in small manufacturing areas, mostly in the North of England. Two counties, Lancashire and the West Riding of Yorkshire, are estimated to have had $65-70 \%$ of adult male labor employed in the secondary sector as early as 1750 . Those hotspots later underpinned the wider industrial revolution, but the concentration of activity persisted: Shaw-Taylor and Wrigley (2008) show that even as late as $1851,60 \%$ of the national labor force in the secondary sector was located in less $17.7 \%$ of registration districts. ${ }^{5}$ The evidence for the UK in Wrigley et al. (1997) is that geographical differences in population growth resulted largely from migration rather than differential fertility and mortality rates. ${ }^{6}$.

During the eighteenth century, the share of labor employed in the secondary sector increased in the North while it decreased in the South. Northern counties taken as a whole increase the secondary employment share

\footnotetext{
${ }^{5}$ The registration district is an administrative unit between parish and county. Clearly these will be of different geographical size since there will be some balancing out of population per district. Because more densely populated districts are likely to be the smaller districts this figure of $17.7 \%$ districts will be an over-estimate of the corresponding proportion of land.

${ }^{6}$ Regional differences in fertility and death rates were relatively minor. Rural-urban differences in fertility rates were not significant, while differences in mortality rates go in the wrong direction to help explain the patterns in Shaw-Taylor et al. (2010b)
} 
from 47 to $62 \%$ between c.1710 to 1817 , while primary employment declines; Southern counties experience the opposite, a deindustrialisation of the labor force from 39 to $28 \%$ share while the primary share increases (see ShawTaylor et al., 2010b; Tables 6 and 7). ${ }^{7}$

Differences in wages across the country point to the drivers of migration. As Hunt (1986) describes, up to the mid-eighteenth century high wage counties were found in the South and East, with low wage counties in the North. That situation is reversed by the end of the eighteenth century, with an acceleration in the Northern real wages relative to the Southern ones also shown in Clark (2001). That early wage advantage in the South is consistent with other evidence that the agricultural improvements which predated the industrial takeoff of the nineteenth century were concentrated in the South of England. Allen (2004) reports that, at least in terms of the scale of farming, agricultural producers in Southern parts of England were the more efficient through the eighteenth century. Shaw-Taylor (2005) shows that consistent differences in farm scale persist into the mid-nineteenth century.

As noted by Wrigley (2010a, p.206), the industrial revolution would not have been possible without 'breaking free from dependence upon photosynthesis... coal provided the escape route'. The innovations in textiles which underpinned the industrial revolution were highly energy-intensive and relied on a supply of cheap energy. While Clark and Jacks (2007) argues convincingly that technological change in the extraction of coal was not responsible for the industrial revolution, Allen (2009) emphasises that the location of that coal and the costs of transporting it could matter to industrial firms' decisions about investments in new technologies. In England, the major source of coal was in the North, around Newcastle and in Lancashire. The large, pre-industrial coal trade entailed the transport of coal from the North to London for heating of domestic and commercial premises. Allen (2009) and Clark and Jacks (2007) put the cost of coal in London at seven times that in Newcastle. Moreover, as indicated in Allen (2009), the costs of trans-

\footnotetext{
${ }^{7}$ For these calculations, Northern counties are Cheshire, Lancashire and all of Yorkshire. Southern counties are Bedfordshire, Buckinghamshire, Cambridgeshire, Huntingdonshire, Northamptonshire, Oxfordshire, Rutland and Wiltshire.
} 
porting that coal was not uniform. In particular, transport infrastructure was better in the North of England. Bagwell (1974, p.15) locates the 'cradle of the canal age proper' to early eighteenth century Lancashire. We can also see this in the Shaw-Taylor et al. (2010a) data for c.1817: In the North of England, $6.0 \%$ of adult male labor was engaged in transportation services while in the South the share is only $2.8 \%$. Until the arrival of railways in the mid-nineteenth century, transportation South of the Midlands of England was costly and this was reflected in high prices in London.

To summarise, the early economic geography of England was established well in advance of what we normally think of as the industrial revolution and remained relatively stable. Aggregate changes in employment shares resulted mainly from migration from agricultural areas to highly concentrated hotspots of industrial activity in the North. The share of labor employed in industry is high well in advance of the takeoff in aggregate growth. Agricultural productivity improvements occurred in advance of the takeoff and away from the Northern hotspots. A significant deindustrialisation of the South occurred in advance of the wider takeoff in growth that occurred into the nineteenth century. Finally, the location of coal was highly concentrated in the North and the cost of transporting it across the country was large and non-uniform.

\section{A Model of Spatial Takeoff}

To capture the detail of the geographical heterogeneity noted above we need a model of continuous space. Important contributions to understanding space and agglomeration have been made in models featuring a small number of countries or regions (e.g., Grossman and Helpman, 1991). In such models, the fixed number of distinct spatial units must remain small to retain tractability and so the generality of such models is limited. They are unable to capture the rich evolution of spatial patterns we see in reality. Models of space with a continuum of regions such as Fujita et al. (2001) can capture the finer detail of spatial patterns, but have not yielded models that can generate quantitative predictions that can be compared with data. Compounding these difficulties 
in the context of development is the need to model the evolution of space over time. Recent attempts to understand such problems in a general way have made progress (e.g., Boucekkine et al., 2009) but omit important features such as trade costs, are highly complex and have generated few clear insights.

A recent approach that retains tractability and can be taken to data is Desmet and Rossi-Hansberg (forthcoming; henceforth DR-H). In that model, firms are located at a point in one-dimensional space and use land and labor to produce manufacturing goods or services. The costliness of trade across space and local diffusion of technology encourages agglomeration while congestion from diminishing returns to labor at each location encourages dispersion. At each point in space that tension determines economic activity. Such models are hard to solve because the distribution of activity determines the amount of trade between locations, while the costliness of that trade determines firm decisions. Rossi-Hansberg (2005) provides a tractable solution concept that can be computed numerically. The advance in DR-H is that firms can invest in risky innovation to expand potential output. Ordinarily, the investment decision of firms would mean that the firm problem is a dynamic one, but DR-H shows how, under assumptions on diffusion and factor mobility, firm decisions about investing in new technology can be modelled in a static way at the same time as having dynamic implications. Manufacturing and services endogenously grow at a constant rate in the long-run. The model is able to match a number of quantitative and qualitative features of spatial development in the US over the period 1980-95.

The model of spatial takeoff in this paper is an extension of the DR-H framework to non-homothetic preferences and different costs to innovation in each sector. By parameterising this model, we are able to match a number of the macroeconomic features of the first industrial revolution as well as some geographical heterogeneities of structural transformation. Subsequent work will look to extend this work to consider a number of issues that mattered historically and today. In particular, there is no capital, so growth results solely from technological progress. Finally, there is no population change and takeoff does not occur following a demographic transition in the manner of a unified growth theory such as Galor (2005) or Desmet and Parente 
(2012). Each of these are clearly important to a fuller picture, but some evidence suggests we might neglect them in a first look at the importance of space to takeoff: For example, Mokyr (2004) attributes 70-80\% of aggregate growth over the period to TFP; Wrigley et al. (1997) does not find significant geographical differences in birth and death rates in England over the period. Nevertheless, incorporating these additional issues into future work will be necessary to provide a more complete picture of the role of geography in economic takeoff and its relevance in low income countries today.

\subsection{Preferences, Geography and Labor}

As in DR-H, the economy is composed of firms that are geographically ordered on the closed interval $[0,1]$. A location is a point $\ell \in[0,1]$, and the density of land at each point is one, so the total mass of land is also one. Agents are infinitely-lived, perfectly mobile and provide labor inelastically. We treat the total number of agents as a fixed number $\bar{L}$. Each agent holds a diversified portfolio of land and firms, with per agent land rents $\bar{R}(t) / \bar{L}$.

An agent in location $\ell$ at time $t$ receives wage $w(\ell, t)$. Agents have preferences over the consumption of agricultural and manufacturing goods, $c_{A}$ and $c_{M}$ respectively. Consumption takes place from the location $\ell$ at which they work and so can involve the costly transportation of goods from the producer. Agents choose consumption bundles to solve,

$$
\begin{gathered}
\max _{\left\{c_{A}(\ell, t), c_{M}(\ell, t)\right\}_{0}^{\infty}} E \sum_{t=0}^{\infty} \beta^{t} U\left(c_{A}(\ell, t), c_{M}(\ell, t)\right) \\
\text { s.t. } \quad w(\ell, t)+\frac{\bar{R}(t)}{\bar{L}}=p_{A}(\ell, t) c_{A}(\ell, t)+p_{M}(\ell, t) c_{M}(\ell, t), \quad \forall(\ell, t),
\end{gathered}
$$

where $p_{i}(\ell, t)$ are prices for each $i \in\{A, M\}$ and $U(\cdot)$ is the instantaneous utility function. There is no storage good. We impose Stone-Geary preferences 
in order to capture the structural transformation away from agriculture, ${ }^{8}$

$$
U\left(c_{A}(\ell, t), c_{M}(\ell, t)\right)=\left(c_{A}(\ell, t)-\gamma\right)^{\eta}\left(c_{M}(\ell, t)\right)^{1-\eta},
$$

with $\gamma>0$ and $\eta \in(0,1)$. Optimisation for each $(\ell, t)$ implies,

$$
\begin{array}{r}
c_{M}^{*}(\ell, t)=\frac{p_{A}(\ell, t)}{p_{M}(\ell, t)} \frac{(1-\eta)}{\eta}\left(c_{A}(\ell, t)-\gamma\right), \\
c_{A}^{*}(\ell, t)=\left[w(\ell, t)+\frac{\bar{R}(\ell, t)}{\bar{L}}+p_{A} \frac{(1-\eta)}{\eta} \gamma\right] \frac{\eta}{p_{A}(\ell, t)} .
\end{array}
$$

The Stone-Geary preferences mean that the marginal utility from the consumption of agricultural goods falls as consumption grows, increasing the optimal share of consumption of manufactured goods. Labor is free to move in advance of productivity realisations. As such, equilibrium prices, wages and rental income are such that agents in all locations receive the same utility, $\bar{u}(t)$, at a given point in time.

\subsection{Technology and Innovation}

At each point in time firms specialise in one sector. Each location houses one firm of the sector that will pay the highest rent for the land. Firms produce either agricultural or manufacturing goods, $A(\ell, t)$ or $M(\ell, t)$, using labor and one unit of land,

$$
\begin{array}{r}
A(\ell, t)=Z_{A}(\ell, t) L_{A}(\ell, t)^{\alpha}, \\
M(\ell, t)=Z_{M}(\ell, t) L_{M}(\ell, t)^{\mu},
\end{array}
$$

\footnotetext{
${ }^{8}$ The advantage of the Stone-Geary preferences is that it allows us to capture a shift away from agriculture that results simply from greater overall consumption, first via agricultural innovation and then (more rapidly) via manufacturing innovation. Alternatives include preferences à la Sato (1977), where weights on each type of consumption in a CES utility specification are a function of, for example, income or wealth. Laitner (2000) imposes that marginal utility from agricultural good consumption is zero once a minimum amount is reached. For the industrial revolution in Britain, Crafts (1985) estimates the income elasticity of agricultural good consumption to be 0.7 , so the Stone-Geary specification captures the idea that agricultural consumption will increase, but that the proportion decreases as income grows.
} 
where $\alpha<\mu$ would reflect greater land-intensiveness in agriculture. For $i \in\{A, M\}, Z_{i}(\ell, t)$ are sector-, time- and location-specific productivity levels and $L_{i}(\ell, t)$ is labor employed by sector $i$ at location $\ell$ in time $t$.

Between time periods technology diffuses across space, declining with distance according to parameter $\delta$. A firm at location $\ell$ has access at the start of time $t$ to a $Z_{i}$ that is the maximum of all other spatially-diffused past productivities (including their own),

$$
Z_{i}(\ell, t)=\max _{r \in[0,1]} e^{-\delta|\ell-r|} Z_{i}(r, t-1)
$$

Observing the start of period technology endowment, firms choose whether and how much to invest in innovation which could increase $Z_{i}(\ell, t)$. Each firm in sector $i$ can decide to buy a probability $\phi$ of innovation at a cost $\psi_{i}(\phi)$. A firm that succeeds in innovating draws a $\hat{z} \geq 1$ from a Pareto distribution,

$$
\operatorname{Pr}[\hat{z}>z]=\left(\frac{1}{z}\right)^{a_{i}}
$$

where $a_{i}>1$ is sector dependent: $a_{A}>a_{M}$ implies that the average manufacturing innovation is greater than the average agricultural innovation. The $\hat{z}>1$ that arrives yields new technology level $\hat{z} Z_{i}(\ell, t)$. The expected value of that innovation increment is $E(\hat{z})=\left(a_{i} /\left(a_{i}-1\right)\right)$. A firm that chooses to invest expects to obtain increment $E(\hat{z})$ with probability $\phi$ and no increment with probability $(1-\phi)$. So the expected technology for a firm that invests is,

$$
E\left(Z_{i}(\ell, t) \mid Z_{i}\right)=\left(\phi \frac{a_{i}}{a_{i}-1}+(1-\phi)\right) Z_{i}=\left(\frac{\phi}{a_{i}-1}+1\right) Z_{i}
$$

We assume that the innovation draws are spatially correlated such that firms arbitrarily close to each other receive the same innovation. ${ }^{9}$

Deciding the path of innovation investment is the only potentially dy-

\footnotetext{
${ }^{9}$ If that were not the case, an infinite number of individual unbounded innovation draws combined with continuous technology diffusion would lead to infinite productivity in all cases. For the purposes of the numerical exercises, it is sufficient that we split the continuum of locations into a finite number of 'counties', within which each firm obtains the same realisation (see DR-H).
} 
namic problem. Given diffusion, profits from an innovation draw are lost in the next period because new entrants can compete with the same technology. Labor is chosen optimally and land is competitive, so rents are such that firms make zero expected profits. Then, the optimal investment in innovation maximises the current payoff (see Proposition 1 in DR-H),

$$
\max _{\phi} p_{i}(\ell, t)\left(\frac{\phi}{a_{i}-1}+1\right) Z_{i} \hat{L}_{i}(\ell, t)^{\imath}-w(\ell, t) \hat{L}_{i}(\ell, t)-\hat{R}_{i}(\ell, t)-\psi(\phi(\ell, t)),
$$

where $\imath=\{\alpha, \mu\}$ and $\hat{L}_{i}$ is optimal $L_{i}$ and $\hat{R}_{i}$ is the competitive rental rate bid. A firm that chooses to invest in innovation thus sets $\phi_{i}$ to maximise the expected net current-period gain from investing,

$$
\max _{\phi_{i}} p_{i}(\ell, t)\left(\frac{\phi_{i}}{a_{i}-1}\right) Z_{i} \hat{L}_{i}(\ell, t)^{\imath}-\psi\left(\phi_{i}(\ell, t)\right)
$$

Following DR-H, we assume that there can be both fixed and marginal costs to firms that wish to innovate. We assume that these costs can differ across sectors. In agriculture, the fixed costs are constant across space. In manufacturing, the fixed costs are related to the cost of energy which can vary. The distinguishing feature of the rapidly-growing sectors in the industrial revolution was their application of energy-intensive technological improvements (see, e.g., Deane and Cole, 1967). As such, we impose that manufacturing firms that innovate also incur energy costs,

$$
\psi_{i}(\phi)=\left\{\begin{array}{ccc}
\psi_{1, i}+\psi_{2, i}\left(\frac{1}{1-\phi}\right)+\Gamma_{i} \xi(\ell) & \text { if } & \phi>0 \\
0 & \text { if } & \phi=0
\end{array},\right.
$$

where $\xi(\ell)$ is the energy cost at location $\ell, \psi_{1, i}>0$ and $\psi_{2, i}>0$ and $\Gamma_{i}=1$ if $i=M$ and 0 otherwise. So firms invest in innovation if the net gain is strictly positive,

$$
\phi_{i}(\ell, t)=\left\{\begin{array}{ccc}
0 & \text { if } & \psi_{i}\left(\phi_{i}^{*}(\ell, t)\right) \geq p_{i}(\ell, t)\left(\frac{\phi_{i}^{*}(\ell, t)}{a_{i}-1}\right) Z_{i} \hat{L}_{i}(\ell, t)^{\imath} \\
\phi_{i}^{*}(\ell, t) & \text { if } & \psi_{i}\left(\phi^{*}(\ell, t)\right)<p_{i}(\ell, t)\left(\frac{\phi_{i}^{*}(\ell, t)}{a_{i}-1}\right) Z_{i} \hat{L}_{i}(\ell, t)^{\imath}
\end{array},\right.
$$


where,

$$
\phi_{i}^{*}(\ell, t)=1-\left(\frac{\psi_{2, i}\left(a_{i}-1\right)}{p_{i}(\ell, t) Z_{i}(\ell, t) \hat{L}_{i}(\ell, t)^{2}}\right)^{1 / 2}
$$

is the solution to (11) given the cost structure (12). Notice that there is a scale effect in the innovation probability: The more labor in a location, the greater the (chosen) probability of obtaining an innovation. Like DR-H, in simulations we make $\psi(\cdot)$ proportional to wages and we make the energy cost, $\xi$, proportional to firm output. The first assumption ensures that the cost of innovation grows if the economy grows (and so wages increase); the second means that energy costs do not become trivial as firms become large.

\subsection{Transport, Land and Goods Markets}

Transport of a good across land incurs an iceberg cost: Only $e^{-\kappa|\ell-r|}$ of a good produced at $\ell$ arrives at $r$. Under those conditions, prices must satisfy,

$$
p_{i}(r, t)=e^{\kappa|\ell-r|} p_{i}(\ell, t)
$$

so then the price of a good increases in the distance that it has to be shipped (the buyer at $r$ is paying for more to be produced at $\ell$ than he is actually consuming). Land goes to a firm in the sector that values it most,

$$
R(\ell, t)=\max \left\{R_{A}(\ell, t), R_{M}(\ell, t)\right\} .
$$

Let $\theta_{i}(\ell, t)=1$ if firm the firm at $\ell$ produces in sector $i$ at time $t$. Equilibrium in goods markets must take account of the transport cost. After Rossi-Hansberg (2005), let $H_{i}(\ell, t)$ denote the stock of excess supply of good $i$ between locations 0 and $\ell$. We define $H_{i}(\ell, t)$ by $H_{i}(0, t)=0$ and the partial differential equation,

$$
\frac{\partial H_{i}(\ell, t)}{\partial \ell}=\theta_{i} x_{i}(\ell, t)-c_{i}(\ell, t)\left(\sum_{i} \theta_{i}(\ell, t) \hat{L}_{i}(\ell, t)\right)-\kappa\left|H_{i}(\ell, t)\right|,
$$

where $\kappa>0$ and $x_{i}(\ell, t)$ is net production of $i$ at $\ell$. The expression (17) has 
two components: First, excess supply of a good increases at a location $\ell$ by the amount of production in that sector less consumption in that location of that good. Second, if excess supply of a good is positive it must be shipped further and thus diminishes according to the transport cost at rate $\kappa$; if it is negative, it must become more negative to account for the loss of goods being shipped in the opposite direction (that is, gross excess demand increases). A consideration of differences in transport costs across the economy and across sectors would permit a consideration of differences in infrastructure supply. For this model we maintain $\kappa$ to be constant. Equilibrium in the goods market is thus defined by $H_{i}(1, t)=0$ for each $i$ and all $t$.

Equilibrium in the labor market requires that the sum of labor allocated in each sector across space, that is,

$$
\int_{0}^{1} \sum_{i} \theta_{i}(\ell, t) \hat{L}_{i}(\ell, t) d \ell=\bar{L} .
$$

An equilibrium is defined as optimal consumption decisions by agents at each $\ell$ and for all $t$, as well as optimal labor purchases by firms, optimal price, land rent- and wage-setting by firms, and optimal innovation decisions. Excess supply of each good is zero at the location $\ell=1$ and total labor employed is equal to total labor supply.

\section{Calibration}

Our focus in the initial quantitative exercise is to match 150 periods of simulation output against 150 years of data covering 1710-1860. Prior to the takeoff in aggregate per capita growth there was a degree of specialisation of the North in industry and the South in agriculture. As described above, the North of England appeared to industrialise in terms of employment shares in the eighteenth century while the South deindustrialised. Moreover, the slow technological change in agriculture happened in advance of the wider takeoff and appears to have been concentrated in the South of England.

The key part of model initialisation is establishing the initial productivity 
distribution in each sector along an interval. We treat the economic geography of England as a one-dimensional North-South line and infer the initial productivity levels in each sector across space along that line using data on occupational geography. In simulations, this interval is treated as a discrete number of spatial units, which we set to be 500. Figure 1 depicts such a 500unit interval against a map of England with $\ell=1$ being the Southern tip (Scilly Isles) and $\ell=500$ the Northern (Berwick upon Tweed). The method of extracting productivity levels is to first sum observed labor in each of the 500 units along the East-West dimension. We can then obtain initial productivity levels consistent with that distribution of labor. ${ }^{10}$ Shaw-Taylor et al. (2010a) contains occupational information at c.1710 for around $10 \%$ of the total number of just over 11,000 parishes. The first step is thus to construct an estimate of the complete occupational geography of England in c.1710.

\subsection{Constructing c.1710 data}

The c.1710 data in Shaw-Taylor et al. (2010a) includes occupational data for adult males in 1,062 of the 11,102 ancient parishes in England. Kitson et al. (2012) describes the creation of a complete 'census' of adult male employment in England for c.1817, with data matched into the same spatial units as the c.1710 data. To infer missing observations in the c.1710 data, we: 1) Build a regression model of the early period occupational data using the late-period data; 2) use coefficient estimates from those regressions to infer missing data in the c.1710 period; and, 3) aggregate up to a larger spatial unit (624 registration districts) in order to reduce noise and limit the margin for error in the estimates. This works relatively well: The OLS regression of a double-log specification of c.1710 employment on c.1817 employment, c.1817 occupational data and geographical characteristics ${ }^{11}$ obtains an $R^{2}$ of 0.82 . Similarly, the regression models at the level of primary (excluding mining)

\footnotetext{
${ }^{10} \mathrm{I}$ thank a referee for suggesting this method of inferring productivity levels.

${ }^{11}$ The regression is specified as a double-log. Given the large degrees of freedom, we include a number of independent variables and their interactions: Log of late period population, primary, secondary, tertiary, mining and textiles as well as geographic characteristics such as log of parish area, latitude, longitude and distance from London.
} 
and secondary employment perform well, with $R^{2}=0.57$ and $R^{2}=0.66$, respectively. A fuller analysis of this data will be the subject of future work, but Figure 2 depicts the distribution of labor along the North-South interval. The concentration of labor in London is clearly visible around $\ell=135$.

\subsection{Initial productivity levels}

We do not have spatial data for capital, so all differences in productivity are inferred from the distribution of labor. For any $(\ell, t)$,

$$
\begin{array}{r}
Z_{M}(\ell, t)=\frac{L_{M}^{1-\mu}(\ell, t)}{\mu} \frac{w(\ell, t)}{p_{M}(\ell, t)} \\
Z_{A}(\ell, t)=\frac{L_{A}^{1-\alpha}(\ell, t)}{\alpha} w(\ell, t) .
\end{array}
$$

We can use the distribution depicted in Figure 2 for $L_{M}(\ell, 0)$ and $L_{A}(\ell, 0)$ but there are two further issues in calculating (19)-(20) to initialise the model: First, we do not know $p_{M}(\ell, 0), w(\ell, 0)$; and, second, a reasonable diffusion parameter with the productivity levels implied by the labor present in London would mean a large jump in productivity between period 1 and 2. As such, we take the following approach including a date 0 diffusion:

1. Use (19)-(20) to calculate $Z_{M}(\ell, 0), Z_{A}(\ell, 0)$ given c.1710 observations for $L_{M}(\ell, 0), L_{A}(\ell, 0)$ and an initial guess for $p_{M}(\ell, 0), w(\ell, 0)$.

2. Apply diffusion on $Z_{M}(\ell, 0), Z_{A}(\ell, 0)$ to obtain $\tilde{Z}_{M}(\ell, 0), \tilde{Z}_{A}(\ell, 0)$.

3. Using $\tilde{Z}_{M}(\ell, 0), \tilde{Z}_{A}(\ell, 0)$ and initial guesses $p_{M}(\ell, 0), w(\ell, 0)$, solve the model for $\hat{L}_{A}(\ell, 0), \hat{L}_{M}(\ell, 0), \hat{p}_{M}(\ell, 0)$ and $\hat{w}(\ell, 0)$ under no innovation.

4. Use (19)-(20) to calculate $\hat{Z}_{M}(\ell, 0), \hat{Z}_{A}(\ell, 0)$ given $\hat{L}_{A}(\ell, 0), \hat{L}_{M}(\ell, 0)$, $\hat{p}_{M}(\ell, 0)$ and $\hat{w}(\ell, 0)$.

5. Pass $\hat{Z}_{M}(\ell, 0), \hat{Z}_{A}(\ell, 0)$ to date 1 of full model.

Although an initial guess is made for prices and wages, by making sure that the model solves at stage 3 . we ensure we have a distribution of productivity in each sector that captures the observed labor distribution plus prices and 
wages that solve the model. As an example, Figure 3 depicts the initial productivity levels obtained for the simulation in Section 5 .

\subsection{Other parameter values}

Table 3 reports the values of other parameters. The preference parameters $\gamma$ and $\eta$ are chosen such that the aggregate employment shares match the Shaw-Taylor et al. (2010b) data for c.1710-1861. ${ }^{12}$ So parameterised, the Stone-Geary preferences and generate initial structural change and a constant long-run employment share in agriculture of $20 \%$. Clearly other forms of preferences could replicate the larger decline of that share into the twentieth century, but this is sufficient for the period of study here. The manufacturing innovation parameter, $a_{M}$, corresponds to the long-run growth rate of around $2 \%$; that for agriculture, $a_{A}$, produces a long-run rate of growth consistent with a slow growth in agricultural output, less than the doubling every 150 years noted in Allen (2004). Agriculture is relatively more land intensive than manufacturing so $\mu>\alpha$; we use the numbers in Valentinyi and Herrendorf (2008). The transport cost parameter $\kappa=0.008$ generates a spatial focus to productivity investments and the diffusion parameter, $\delta=15$ affects the speed of takeoff and so helps fit the labor shift and aggregate growth takeoff.

The innovation cost functions are parameterised with the same marginal cost parameter across each sector as in DR-H, $\psi_{2, i}=0.002$. We choose the fixed cost parameters to reflect the evidence on agricultural revolution predating the industrial one. Setting $\psi_{1, A}=0.5832$ locates the takeoff agricultural productivity at $t=1$, and $\psi_{1, M}=0.9340$ means no initial manufacturing innovation. The energy costs reflect the evidence in Clark and Jacks (2007) and Allen (2009) that energy prices in London were around seven times that in London, a ratio that remained relatively stable through the eighteenth century. Allen (2009) provides 1700 relative coal energy prices for Northeast, Western UK and London at 7.28, 6.24 and 1, respectively. We locate those prices to the peaks in coal supply at Newcastle $(\ell=428)$, at Lan-

\footnotetext{
${ }^{12}$ There is no tertiary sector in the model, so the shares we look to match are based on the primary:secondary ratio, i.e., declining from $53 \%$ to $35 \%$ over the period.
} 
cashire $(\ell=305)$ and the population peak in London $(\ell=136) \cdot{ }^{13}$ Coal was transported from the coalfields in the North to the population centre in the South, so prices increased as they approach London; we project relative energy prices between and outwith these locations based on the implied iceberg cost. Finally, we let the innovation cost of energy be a proportion of manufacturing output, normalised to 0.05 at $\ell=305$.

The price of agricultural goods is the numeraire, $p_{A}(:, t)=1$ for all $t$.

Table 3: Parameterisation

\begin{tabular}{|c|c|c|}
\hline$\beta$ & 0.95 & Standard discount factor. \\
\hline$\eta$ & 0.2 & To match aggregate employment shares over \\
\hline$\gamma$ & 0.06 & 1710-1860 in Shaw-Taylor et al. (2010b). \\
\hline$\delta$ & 15 & $\begin{array}{l}\text { To match speed of takeoff in Crafts and Harley } \\
\text { (1992). }\end{array}$ \\
\hline$\kappa$ & 0.008 & $\begin{array}{l}\text { Consumption good transport cost in Desmet and } \\
\text { Rossi-Hansberg (forthcoming). }\end{array}$ \\
\hline$a_{M}$ & 70 & Long-run growth of $2 \%$, Heston et al. (2011). \\
\hline$a_{A}$ & 295 & Slow early agricultural growth rate, Allen (2004). \\
\hline$\alpha$ & 0.59 & $\begin{array}{l}\text { Firm-level employment share for agriculture in } \\
\text { Valentinyi and Herrendorf (2008). }\end{array}$ \\
\hline$\mu$ & 0.67 & $\begin{array}{l}\text { Firm-level employment share for manufactured } \\
\text { consumption in Valentinyi and Herrendorf (2008). }\end{array}$ \\
\hline$\psi_{1, A}$ & 0.5832 & A takeoff in agriculture at $t=1$ \\
\hline$\psi_{1, M}$ & 0.9340 & $\begin{array}{l}\text { Timing of manufacturing takeoff as in Crafts and } \\
\text { Harley (1992). }\end{array}$ \\
\hline$\psi_{2, A}, \psi_{2, M}$ & 0.002 & \\
\hline$\xi(\ell)$ & See text & $\begin{array}{l}\text { Coal prices from Allen (2009), Clark and Jacks } \\
(2007) \text {. }\end{array}$ \\
\hline $\begin{array}{l}Z_{A}(\ell, 0) \\
Z_{M}(\ell, 0)\end{array}$ & See text & $\begin{array}{l}\text { Data in Shaw-Taylor et al. (2010b) and own } \\
\text { working. }\end{array}$ \\
\hline $\bar{L}$ & 100 & Normalised total labor supply. \\
\hline
\end{tabular}

\footnotetext{
${ }^{13}$ These peaks in coal supply are identified using the c.1817 distribution of adult male coalworkers; they align with the coalfields at Newcastle and Lancashire.
} 


\section{$5 \quad$ Equilibrium Outcomes}

Individual simulation outcomes are analytical solutions that depend on individual realisations of technology shocks at each point in space over time. As such, there is some volatility in average growth rates that results from discretising the $[0,1]$ geography into 500 'counties' and manufacturing can appear relatively more volatile by virtue of being an average of fewer discrete technology shocks. The timing of takeoff can vary slightly between individual simulations based on the same initial conditions and parameters.

Figures 4 report 150 periods of an individual simulation outcome. The panels of each figure depict different aspects of the equilibrium outcome and we refer to a panel of a figure as Figure f.r.c where $f$ is the figure number, $r$ is row and $c$ is column.

Figure 4.1.1 reports the growth rate of output in each sector averaged across all locations; blue is manufacturing growth, red is agriculture and green is the aggregate growth rate. The thick lines are six-period moving averages of the growth rates. There is initially a slow takeoff in agricultural productivity. Higher consumption reduces the marginal utility from consuming agricultural goods and increases the demand for manufactured goods. Initially, that increased demand is supplied by expanding the land used for manufacturing to the low-productivity North, as can be seen in Figure 4.1.2. That shift in land use toward manufacturing initially reduces the aggregate productivity of manufacturing firms, as can be seen in after $t=40$ in Figure 4.2.1 which reports aggregate productivity in each sector. Once enough labor has shifted out of agriculture, at $t=61$, some firms reach a scale sufficient to overcome the fixed costs to innovation and begin to innovate in manufacturing. Thereafter, the decline average productivity in manufacturing slows before turning upwards. Figure 4.2 .2 depicts the stock of excess supply in manufacturing, $H_{M}(\ell, t)$ at each location, where different lines are drawn for different time periods (higher lines are earlier time periods).

Figure 4.3.1 reports the average relative price of manufactured goods. While agriculture is the only sector innovating, the relative price of manufactured goods increases; once the takeoff occurs, the faster rate of tech- 
nological progress in manufacturing means that its relative price eventually declines. Figure 4.3.2 depicts employment share in agriculture (red) as well as the share of consumption that is manufacturing goods (green).

The locations of innovation are as follows: Agricultural innovation happens in the South from $t=0$ because of the relatively high agricultural productivity there and also because of the large population of consumers in London. Takeoff in manufacturing, i.e., the first investment in new technologies, happens at $t=61$ and $\ell=305 .{ }^{14}$ This location represents a compromise between distance from the population centre, the cost of energy across space and the initial productivity in manufacturing. Despite the advantage that London has in its relatively high initial manufacturing productivity, the energy costs involved in investing in energy-intensive technologies are too great and so the industrial revolution begins in the North.

\subsection{The model against data}

We first compare the model implications against aggregate data for the first industrial revolution. Figure 5 depicts the simulation output against data for growth, employment shares, wages, relative prices and land rents. ${ }^{15}$ The simulation output matches aspects of the data quite well. In particular, the observed takeoff in growth matches the speed and magnitude of the takeoff in the simulation aggregate growth rate. We match the small change in employment share closely. The long-run share in agriculture in the model is $20 \%$ and so clearly the assumption of Stone-Geary preferences would not be adequate to match the decline of the agricultural employment share into the twentieth century. Relative prices are somewhat more volatile than in the data, at first increasing slightly because of the takeoff in agricultural productivity. Once the industrial innovation begins, the relative price of manufacturing declines rapidly. As will be seen in Section 7 , some of the decline in the relative price is mitigated by incorporating international trade. The simulation path of real wages and land rents tracks the takeoff in the

\footnotetext{
${ }^{14}$ Over thirty simulations, the average takeoff time is 57.0; standard deviation of 3.3.

${ }^{15}$ See Appendix A for information on data sources.
} 
data and the model implications for price of manufacturing relative to wages peaks around the same point as in the data.

We can also use the occupational geography data in Shaw-Taylor et al. (2010a) for c.1817 and 1861 to evaluate the model performance in predicting the spatial distribution of labor in each sector. As with the c.1710 data, we calculate the distribution of labor along an interval. Since in the model there is no population growth, the total labor supply in the data is normalised across the three periods.

Figure 6 shows the change in the distribution of labor in the primary sector. Technological change in agriculture is located in the South around London, which matches the historical literature described above. Since substantial portions of land which in the data are at least partly agricultural are given up wholly to manufacturing firms, the model implies that agricultural labor is somewhat more spatially concentrated than is evident in the data.

Figure 7 depicts the distribution of labor in the secondary sector against the data. The location of the manufacturing hotspot fits the data very well and, for 1817, comes close to the right magnitude. The disappearance of London as a secondary producer is notable. One issue is that we are comparing data for multiple secondary sectors with a model that has only one secondary sector. As discussed above, the one sector that drove the industrial revolution was textiles. Figure 8 depicts the same model output against (rescaled) data for textiles. ${ }^{16}$ Clearly, the model does a good job of matching the data for textiles alone. Both the location and magnitude are captured at both 1817 and 1861, while the disappearance of London fits the data.

That specialisation of the North into industry and South into agriculture suggests an important role for the tertiary sector, especially in wholesaling and transportation of goods longer average distances. A major conclusion of the Shaw-Taylor et al. (2010b) study is that, in the nineteenth century, the tertiary sector was by far the most dynamic in terms of its share of labor across the country. However, the model generates complete long-run special-

\footnotetext{
${ }^{16}$ The sample of observations for c.1710 in Shaw-Taylor et al. (2010b) represent the North of England better than the South. While the estimates for the North are thus relatively reliable, they possibly under-estimate textile employment in the South West. See Randall (1991) for a discussion of the two textile regions.
} 
isation of the South in agriculture and North industry which is not consistent with the nineteenth century experience in England. The importance of this initial specialisation, the later spread of high-productivity industry to the South and the role of the tertiary sector are all important topics for further study. For now, Sections 6 to 8 considers a number of counterfactual experiments. ${ }^{17}$

\section{Geographical Counterfactuals}

Figure 9 gives the original distribution in Panel A and three transformations that keep the same aggregate average productivity but vary the distribution of that productivity across space. In all the geographical counterfactuals we keep agricultural productivity and all other parameters as in Section 5.

Distribution B simply flattens the whole distribution. Again, the South specialises in agriculture while the North specialises in manufacturing. Since the manufacturing labor previously concentrated in London is now evenly spread over Northern locations, nearly all manufacturing firms located in the North are of a scale sufficient to engage in investments in innovation. They also benefit from the low energy costs as they sit on top of the source of cheap energy and so industrial takeoff happens immediately and widely.

The effect of redistributing the labor in London appears to dominate the outcome in Panel B. In contrast, Panel C of Figure 9 retains the productivity peak in London and flattens the productivity distribution elsewhere. ${ }^{18}$ In the short-run, the model behaves as in the baseline case; London dominates secondary output with agricultural innovation situated nearby and slow growth in aggregate output. Since agricultural productivity is relatively low in the Northern and Southern tips, small areas of manufacturing productivity exist there. In the absence of the regions of relatively high productivity in the North, at no point over these 150 periods do firms engage in manufacturing innovation expenditure. As agricultural innovation proceeds, the relative

\footnotetext{
${ }^{17}$ Simulation output for the counterfactual exercises is generally not reported for reasons of space, but is available from the author.

${ }^{18}$ London is, for this counterfactual, defined as $\ell \in[101: 174]$.
} 
price of manufacturing increases over time and the rental value of land to manufacturers increases. The spread of manufacturing land takes the form of the Northern and Southern regions expanding toward London, but there is no investment in innovation by manufacturing firms.

Finally, Panel D of Figure 9 reports the distribution of productivity which results from applying a smoothing filter to the original manufacturing productivity distribution. ${ }^{19}$ The equilibrium outcome with the smoothed distribution behaves as with the distribution in Panel C: There is substantial manufacturing output in London and some agricultural innovation in the South. Greater output of manufacturing goods again comes via expanding land used by manufacturing firms, except now they are located atop the relatively high-productivity manufacturing areas. Despite some peaks in manufacturing productivity in the North, they are not sufficient to generate endogenous growth in manufacturing over the 150 periods.

The role of geographically-small regions of high productivity growth whether it be London dominating early employment in manufacturing or the concentration of productivity in the North of England - appear key to explaining an industrial takeoff.

\section{International Trade}

The UK was a net importer of foodstuffs and a net exporter of manufactured goods by the end of the eighteenth century. Net exports of manufactures were around $6.2 \%$ of national output in 1700 , increasing to around $17 \%$ of output by $1855 .{ }^{20}$ We consider the impact of this trade on takeoff, as well as ask whether the location of the entry of that trade into England could have affected the location or timing of takeoff.

Many factors outside of the model determined the level of trade into and out of England during this period. As such, we consider the impact of

\footnotetext{
${ }^{19}$ We use a Savitzky-Golay filter with polynomial order 3 and frame size 61.

${ }^{20}$ We use trade and population data from Davis (1962) and Mitchell (1988) to construct a series for net trade per capita. See Table A. The correlation coefficient between net exports of manufactures and net imports of agricultural goods is 0.98 .
} 
international trade on equilibrium outcomes in a simple way by assuming an exogenous flow of trade to ports. Exports which depart at a location $\ell$ can be modelled as an exogenous decrease in the excess supply function, $H_{M}(\ell, t) \cdot{ }^{21}$ In the model we approximate the increase in trade over time by a linear trend fitted to the data. ${ }^{22}$ We calculate the net international manufacturing trade at a location $\ell$ in time $t$ as a proportion of period $t-1$ total manufacturing output using the linear trend in manufacturing openness.

We first consider the impact that trade through London (location $\ell=$ 135) has on the timing of the takeoff. Under the same parameterisation as Table 4, introducing trade causes takeoff to happen around twenty five years earlier. The presence of a significant external demand for manufactured goods increases the relative price of manufacturing, hastens the shift of labor into manufacturing and means that Northern firms reach the scale sufficient for takeoff earlier than they would otherwise do. For comparison with the simulation in Section 5, we increase the fixed cost of manufacturing to $\psi_{1, M}=$ 0.999 which locates the timing of takeoff closer to that consistent with the data. Average prices of manufactured goods are slightly higher because of the additional demand for manufactured output but do not clearly match the data better. The shift of labor out of agriculture is now much faster, declining to nearly $20 \%$ over the 150 year simulation.

We can also consider the role of the location of the imports on the timing of takeoff. As Armstrong and Bagwell (1983) describes, although the eighteenth century coastal trade was dominated by London, by 1841 the port at Liverpool $(\ell=295)$ was the third most important (after London and the coal port at Newcastle). Exogenous exports will tend to increase the relative price of manufacturing around the port, an effect that will be exacerbated if that port is a significant distance from the major production centre (in this case, London) since more output is lost in transportation. Increasing the relative

\footnotetext{
${ }^{21}$ Modelling net imports of agricultural products would have the same impact on the model as exports of manufacturing products. By construction of the excess supply function we know that, at each location $\ell$, the sum of excess supply in one good up to $\ell$ must be offset by an excess demand for the other good up to that $\ell$, i.e., $H_{A}(\ell, t)+p_{M}(\ell, t) H_{M}(\ell, t)=0$ for all $(\ell, t)$.

${ }^{22}$ Using this linear approximation improves computation of simulation outcomes.
} 
price will make it more likely that local firms will reach a scale sufficient to induce investment in innovation. Based on the reparameterised trade model, there is little impact of locating all international trade at $\ell=295$ instead of $\ell=135$. Based on thirty simulations with each export location, the mean takeoff date when goods depart from London is $t=66.7$; exports through Liverpool yield a mean takeoff date of $t=65.8{ }^{23}$ The lack of an effect may be because trade is not substantial enough to have an impact, or because of the relatively low transport cost assumed for the production goods.

\section{Policy}

The model as calibrated in Section 4 allows us to ask what role simple policies might play in affecting when an industrial takeoff begins. We look at the effect of three industrial policies on the location and timing of takeoff: First, subsidies to innovation; second, subsidies to land use; and third, infrastructure development that reduces the costs of transporting coal.

We characterise the time and location of industrial takeoff as the time and location of the first innovative activity in manufacturing. Simulations of the model parameterised according to Table 3 generate an average (over thirty simulations) takeoff date of $t=57$, with a standard deviation of 3.3 years. Takeoff occurs at location $\ell=305$. We would expect that subsidies to technology adoption in manufacturing would bring forward the date of industrial takeoff. Given the role of agricultural innovation in releasing labor into manufacturing, we can also expect a role for subsidies to agricultural innovation. To model a policy that encourages innovation in a particular sector, we reduce the innovation fixed cost by $5 \%$ of the value in Table 3 . The results are given in Table 4, rows II-III. A cut in the fixed cost of agricultural innovation generates a broader takeoff in agricultural productivity and brings forward the industrial takeoff by just over three years without affecting the location of takeoff. Reducing the fixed cost of manufacturing has a larger effect, bringing forward the date of takeoff by over fourteen years

\footnotetext{
${ }^{23}$ The standard deviation of the takeoff time is 7.2 years.
} 
on average. Subsidising manufacturing innovation also has an effect on the location of takeoff, shifting the centre of the industrial productivity growth further North, away from London. This suggests that the main driver of the location of takeoff is not the proximity to the major market, but the price of coal in the location of a possible industrial takeoff.

Table 4: Policy Interventions

\begin{tabular}{cl|ccc}
\hline & & takeoff, $t$ & s.d. & $\ell$ \\
\hline I & baseline & 57.0 & 3.3 & 305 \\
II & $0.95 \cdot \psi_{A, 1}$ & 53.6 & 2.8 & 305 \\
III & $0.95 \cdot \psi_{M, 1}$ & 43.3 & 1.8 & $324-5$ \\
IV & $1.01 \cdot R_{M}$ & 89.3 & 22.6 & 305 \\
V & $1.01 \cdot R_{A}$ & 57.8 & 3.3 & 305 \\
\hline \hline
\end{tabular}

Numbers are based on thirty runs each.

To model policies directed at land use, we introduce a $1 \%$ subsidy to the market rent paid by a sector. As can be seen in Table 4 row IV, encouraging manufacturing land use significantly delays takeoff on average, and makes its arrival less predictable. The gains from spatial-concentration of manufacturing activity appear to be lost when industrial land use is subsidised. Applying a subsidy to agricultural land use has no discernible impact of takeoff, however. In the baseline output (Figure 4), non-innovating manufacturing firms emerge in the North in advance of the takeoff in innovation. Subsidies to agricultural land use may slightly delay this shift into manufacturing land, but it can also make it more concentrated spatially; the net effect on takeoff is limited. Subsidies to manufacturing land use, however, bring forward the emergence of non-innovating manufacturing firms in the North and make them spatially less concentrated. In these simulations, the lower concentration matters more as firms do not reach the scale sufficient for innovation until much later, on average.

Finally, we can consider the role of transport costs. As discussed in Section 2, the historical evidence on the spatial distribution of energy prices implies that the costs of transporting coal were significant and not uniform across the country. We modelled energy prices as increasing in the direction 
of London, with a relatively low transport cost North of $\ell=305$, in a way that reflects the evidence for the early eighteenth century. Investment in new transport infrastructure became increasing important into the nineteenth century (see, for example, Trew, 2010). We can ask how much lower transport costs would have to be South of $\ell=305$ for industrial takeoff to occur close to London $(\ell=135)$ : We need to reduce the price of energy at London by $56 \%$ in order to generate an industrial revolution there. Focusing infrastructure spending on the most significant population centre does not, in this case, seem to be a cost-effective means of inducing industrial takeoff.

\section{Concluding Remarks}

Asking why the industrial revolution happened where it did can help us understand why it happened at all. A model of spatial takeoff, calibrated to new occupational data for the early eighteenth century, is able to match the location and magnitude of the industrial takeoff, as well as a number of other aggregate facts. The importance of the spatial concentration of economic activity for takeoff is clear from the geographical counterfactuals. A number of policy experiments suggest a relatively limited role for government in bringing forward the date of industrial takeoff, but some clear ability to delay it through subsidies to manufacturing land use.

There are a number of issues that merit further study. That the tertiary sector is the most dynamic in the data suggests that it should be modelled explicitly. This seems particularly important given the role played by the locations of coal and the costliness of its transportation. While the importance of infrastructural development to growth has been found in both historical and modern contexts, ${ }^{24}$ a model of spatial takeoff that incorporates a role for investments in infrastructure could imply optimal policies over where to concentrate infrastructural spending to hasten takeoff or to benefit long-run growth. There is evidence ${ }^{25}$ that during the first industrial revolution the

\footnotetext{
${ }^{24}$ See, for example, Calderón and Servén (2004), Atack et al. (2008) and Donaldson (2010)

${ }^{25}$ See Shea (2012) and Trew (2010).
} 
finance of those infrastructures was also spatially concentrated around the early hotspots of activity. Understanding that could add to our understanding of the relationship between financial and economic development more generally.

The demand for the tertiary sector is, in part, a function of spatial specialisation. While the model can capture the deindustrialisation of the South in advance of the takeoff in per capita growth, it cannot account for the later increases in Southern industrial employment observed in the nineteenth century. Modelling these more complicated changes over time would be necessary for a proper study of the tertiary sector. Identifying the role played by London - through its demand for energy and its supply of secondary sector outputs - in the timing of the industrial revolution also appears important.

Finally, the model is initialised at c.1710 based on data that suggests an already relatively high level of manufacturing productivity in the region that became the industrial hotspot. Understanding why the geography of England appeared as it did in the early eighteenth century is necessary to explain fully why the industrial revolution happened in a small part of the North of England.

\section{References}

Allen, R. C. (2004). 'Agriculture during the industrial revolution, 17001850'. Chapter 1 in Floud, R. and Johnson, P. (eds.). The Cambridge Economic History of Modern Britain: Volume 1, Industrialisattion 17001860. Cambridge University Press.

Allen, R. C. (2007). 'Pessimism Preserved: Real Wages in the British Industrial Revolution'. Oxford University, Department of Economics, Working Paper 314.

Allen, R. C. (2009). The British Industrial Revolution in Global Perspective. Cambridge University Press.

Antràs, P. and Voth, H. J. (2003). 'Factor Prices and Productivity Growth during the English Industrial Revolution'. Explorations in Economic History, 40:52-77. 
Armstrong, J. and Bagwell, P. S. (1983). 'Coastal shipping'. Chapter 5 in Aldcroft, D. H. and Freeman, M. J. (eds.). Transport in the Industrial Revolution. Manchester University Press.

Atack, J., Haines, M. R., and Margo, R. A. (2008). 'Railroads and the Rise of the Factory: Evidence for the United States, 1850-70'. NBER Working Paper No. 14410.

Bagwell, P. S. (1974). The Transport Revolution from 1770. B. T. Batsford Ltd. Manchester University Press.

Boucekkine, R., Camacho, C., and Zou, B. (2009). 'Bridging the Gap Between Growth Theory and the New Economic Geography: The Spatial Ramsey Model'. Macroeconomic Dynamics.

Calderón, C. and Servén, L. (2004). 'The Effects of Infrastructure Development on Growth and Income Distribution'. Policy Research Working Paper Number 3400. World Bank.

Clark, G. (2001). 'Farm Wages and Living Standards in the Industrial Revolution: England 1670-1870'. Economic History Review, 54(3):477-505.

Clark, G. (2002). 'The Agricultural Revolution and the Industrial Revolution, England 1500-1912'. Available at http://www.econ.ucdavis.edu/faculty/gclark/data.html.

Clark, G. (2003). 'The Price History of English Agriculture, 1209-1914'. Available at http://www.econ.ucdavis.edu/faculty/gclark/data.html.

Clark, G. (2007). 'The Long March of History: Farm Wages, Population and Economic Growth, England 1209-1869'. Economic History Review, 60(1):97-136.

Clark, G. and Jacks, D. (2007). 'Coal and the Industrial Revolution, 17001869'. European Review of Economic History, 11(1):39-72.

Cottrell, P. L. (1980). Industrial Finance 1830-1914: The finance and organization of English manufacturing industry. Methuen.

Crafts, N. F. R. (1985). British Economic Growth during the Industrial Revolution. Clarendon Press.

Crafts, N. F. R. (1994). 'The industrial revolution'. Chapter 3 in Floud, R. and McCloskey, D. N. (eds.). The Economic History of Britain since 1700: Volume 1, 1700-1860. Cambridge University Press. 
Crafts, N. F. R. and Harley, C. K. (1992). 'Output Growth and the British Industrial Revolution: A Restatement of the Crafts-Harley View'. The Economic History Review, 45(4):703-30.

Davis, R. (1962). 'English Foreign Trade, 1700-1774'. The Economic History Review, 15(2):285-303.

Deane, P. and Cole, W. A. (1967). British Economic Growth 1688-1959. Cambridge University Press.

Desmet, K. and Parente, S. L. (2012). 'The Evolution of Markets and the Revolution of Industry: a Unified Theory of Growth'. Journal of Economic Growth, 17:205-34.

Desmet, K. and Rossi-Hansberg, E. (forthcoming). 'Spatial Development'. American Economic Review.

Donaldson, D. (2010). 'Railroads of the Raj: Estimating the Impact of Transportation Infrastructure'. NBER Working Paper No. 16487.

Fujita, M., Krugman, P., and Venables, A. (2001). The Spatial Economy: Cities, Regions and International Trade. MIT Press.

Galor, O. (2005). 'From Stagnation to Growth: Unified Growth Theory', in Aghion, P. and Durlauf, S.N. (eds.). Handbook of Economic Growth. Elsevier.

Gollin, D., Parente, S. L., and Rogerson, R. (2002). 'The Role of Agriculture in Development'. American Economic Review: Papers and Proceedings, 92(2):160-4.

Grossman, G. and Helpman, E. (1991). 'Quality Ladders in the Theory of Economic Growth'. Review of Economic Studies, 58(1):43-61.

Harley, C. K. (2004). 'Trade: discovery, mercantilism and technology'. Chapter 7 in Floud, R. and Johnson, P. (eds.). The Cambridge Economic History of Modern Britain: Volume 1, Industrialisattion 1700-1860. Cambridge University Press.

Hayashi, D. and Prescott, E. C. (2008). 'The Depressing Effect of Agricultural Institutions on the Prewar Japanese Economy'. Journal of Political Economy, 116(4):573-632.

Henderson, J. V., Storeygard, A., and Weil, D. N. (2011). Measuring economic growth from outer space. American Economic Review. 
Heston, A., Summers, R., and Aten, B. (2011). 'Penn World Table Version 7.0'. Center for International Comparisons of Production, Income and Prices at the University of Pennsylvania.

Hudson, P. (1989). Regions and Industries. Cambridge University Press.

Hunt, E. H. (1986). 'Industrialization and Regional Inequality: Wages in Britain, 1760-1914'. Journal of Economic History, 46(4):935-66.

Kitson, P. M., Shaw-Taylor, L., Wrigley, E. A., Davies, R. S., Newton, G., and Satchell, A. E. M. (2012). 'The creation of a 'census' of adult male employment for England and Wales for 1817'. Work in Progress. For details of the wider project see http://www.geog.cam.ac.uk/research/projects/occupations/.

Laitner, J. (2000). 'Structural Change and Economic Growth'. Review of Economic Studies, 67:545-61.

Langton, J. (1984). 'The Industrial Revolution and the Regional Geography of England'. Transactions of the Institute of British Geographers, 9(2):14567.

Lindert, P. H. and Williamson, J. G. (1982). 'Revising England's Social Tables, 1688-1812'. Explorations in Economic History, 19(4):385-408.

Matsuyama, K. (1992). 'Agricultural Productivity, Comparative Advantage, and Economic Growth'. Journal of Economic Theory, 58:317-34.

Mitchell, B. R. (1962). Abstract of British Historical Statistics. Cambridge University Press.

Mitchell, B. R. (1988). British Historical Statistics. Cambridge University Press.

Mokyr, J. (2004). 'Accounting for the industrial revolution'. Chapter 1 in Floud, R. and Johnson, P. (eds.). The Cambridge Economic History of Modern Britain: Volume 1, Industrialisattion 1700-1860. Cambridge University Press.

Randall, A. J. (1991). Before the Luddites: custom, community and machinery in the English woolen industry. Cambridge University Press.

Rossi-Hansberg, E. (2005). 'A Spatial Theory of Trade'. American Economic Review, 95:1464-91. 
Sato, R. (1977). 'Homothetic and Non-Homothetic CES Production Functions'. American Economic Review, 67(4):559-69.

Shaw-Taylor, L. (2005). 'Family farms and capitalist farms in mid nineteenthcentury England'. British Agricultural History Society, 53(2):158-91.

Shaw-Taylor, L., Davies, R. S., Kitson, P. M., Newton, G., Satchell, A. E. M., and Wrigley, E. A. (2010a). 'The occupational structure of England and Wales c.1817-1881'. Work in Progress. For details of the wider project see http://www.geog.cam.ac.uk/research/projects/occupations/.

Shaw-Taylor, L. and Wrigley, E. A. (2008). 'The occupational structure of England c.1750 to c.1871'. For details of the wider project see http://www.geog.cam.ac.uk/research/projects/occupations/.

Shaw-Taylor, L., Wrigley, E. A., Davies, R. S., Kitson, P. M., Newton, G., and Satchell, A. E. M. (2010b). 'The occupational structure of England c.1710 to c.1871'. Work in Progress. For details of the wider project see http://www.geog.cam.ac.uk/research/projects/occupations/.

Shea, G. S. (2012). 'The Handbook of 18th and Early 19th Century British Corporate Finance'. University of St. Andrews, mimeo.

Trew, A. W. (2010). 'Infrastructure Finance and Industrial Takeoff in England'. Journal of Money, Credit and Banking, 42(6):985-1010.

Valentinyi, A. and Herrendorf, B. (2008). 'Measuring factor income shares at the sectoral level'. Review of Economic Dynamics, 11:820-35.

Wrigley, E. A. (2010a). Energy and the English Industrial Revolution. Cambridge University Press.

Wrigley, E. A. (2010b). 'The PST System of Classifying Occupations'. Paper 1 at www.hpss.geog.cam.ac.uk/research/projects/occupations/britain19c/papers/.

Wrigley, E. A., Davies, R. S., Oeppen, R. S., and Schofield, R. S. (1997). English Population History from Family Reconstitution, 1580-1837. Cambridge Studies in Population, Economy and Society in Past Time. Cambridge University Press.

Yang, D. T. and Zhu, X. (2009). 'Modernization of Agriculture and LongTerm Growth'. 


\section{A Data Sources}

\begin{tabular}{ll} 
Variable & Description \\
\hline Per capita growth & The Crafts and Harley (1992) measures of British aggregate per \\
& capita growth cited in Mokyr (2004). \\
Employment shares & From Shaw-Taylor et al. (2010, Table 4), the current best guesses \\
& for England's male occupational sectoral distribution. Regional \\
& shares are from op. cit. (Table 6); Northern counties are Cheshire, \\
& Lancashire, East Riding of Yorkshire, North Riding of Yorkshire \\
& and West Riding of Yorkshire. Southern counties are Bedfordshire, \\
& Buckinghamshire, Cambridgeshire, Huntingdonshire, Northamp- \\
& tonshire, Oxfordshire, Rutland and Wiltshire. The numbers used \\
& in the figures omit the tertiary figures, i.e., they are the pri- \\
& mary:secondary ratio over time. \\
& We construct relative prices as in Yang and Zhu (2009). The agri- \\
& cultural price index is the annual series 'Farm Index' from Clark \\
& (2003, Appendix Table 4). The manufacturing price is composed \\
& of the Schumpeter-Gilboy and the Rousseuax price indices from \\
& Mitchell (1962, Prices Tables 1 and 3). The relative price series is \\
& the ratio of decadal averages of each of the annual series. \\
& Aggregate real wage index from the data collected in Clark (2002, \\
& Table 1). The price of manufacturing relative to wages is con- \\
structed with decadal averages of each series. Alternative perspec- & tives on the real wage series are available in, for example, Allen \\
Real wages & (2007), but the comparisons between the simulation output and \\
data are similar. & An index of land rents including local taxes paid by property oc- \\
cupiers from the data collected in Clark (2002, Table 1) & The trade data for foodstuffs and manufactures over the period \\
& 1699-1701 to 1772-4 are for England from Davis (1962); that for \\
& 1785-1855 are for Great Britain from Mitchell (1988). The data is \\
deflated using the relative price series constructed as in Yang and \\
Zhu (2009) (see above) and converted into per capita terms using \\
population data in Mitchell (1988). Harley (2004) has exports as \\
a share of national output at 20\% in 1885. We use that with the \\
Crafts and Harley (1992) per capita growth data to create the share \\
of net exports of manufacturing.
\end{tabular}




\section{B Figures}

Figure 1: The England Interval, [0,500]

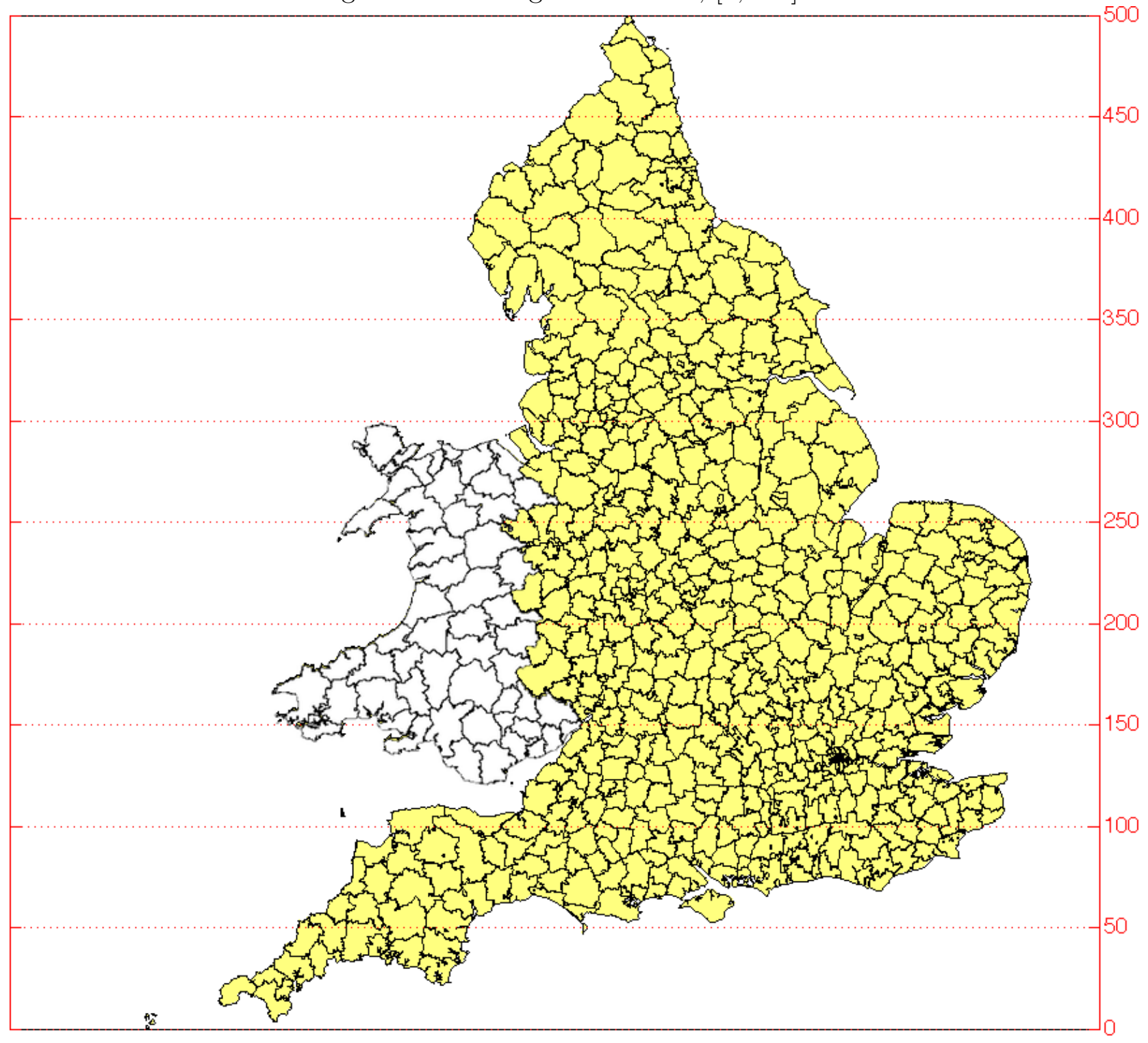


Figure 2: Primary and Secondary Employment, c.1710

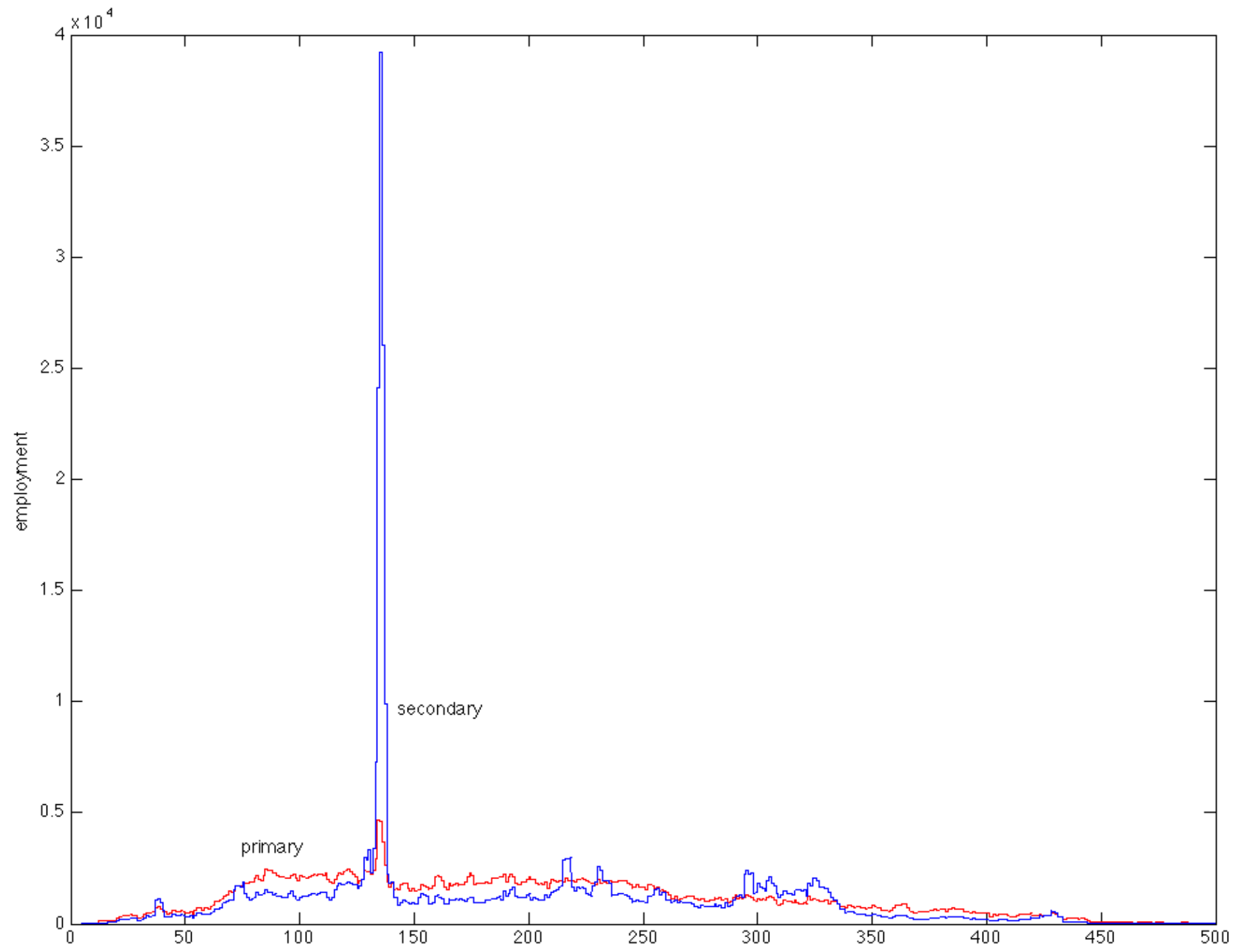


Figure 3: Initial Productivity, Primary (left) and Secondary (right)
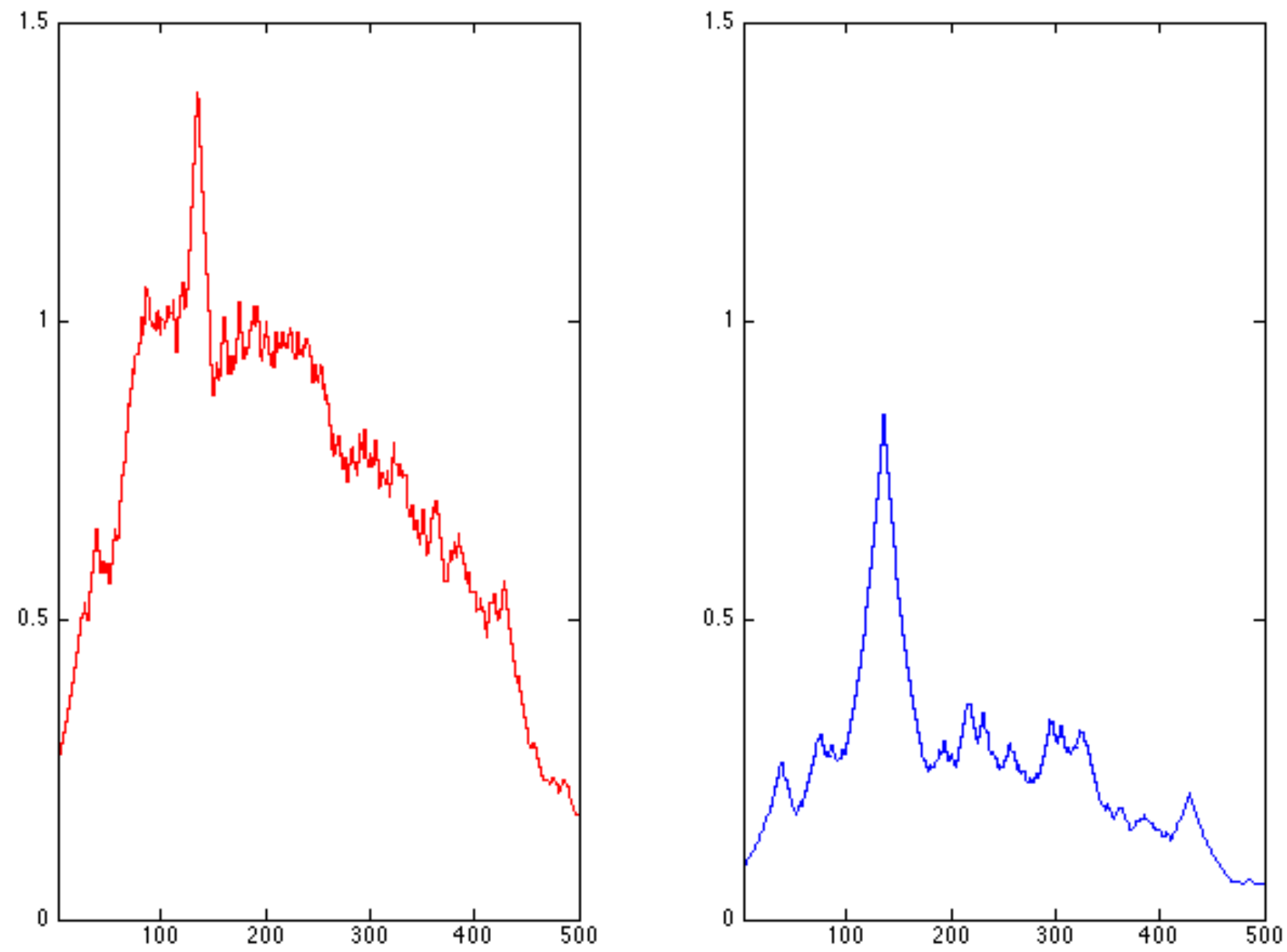
Figure 4: Model Output
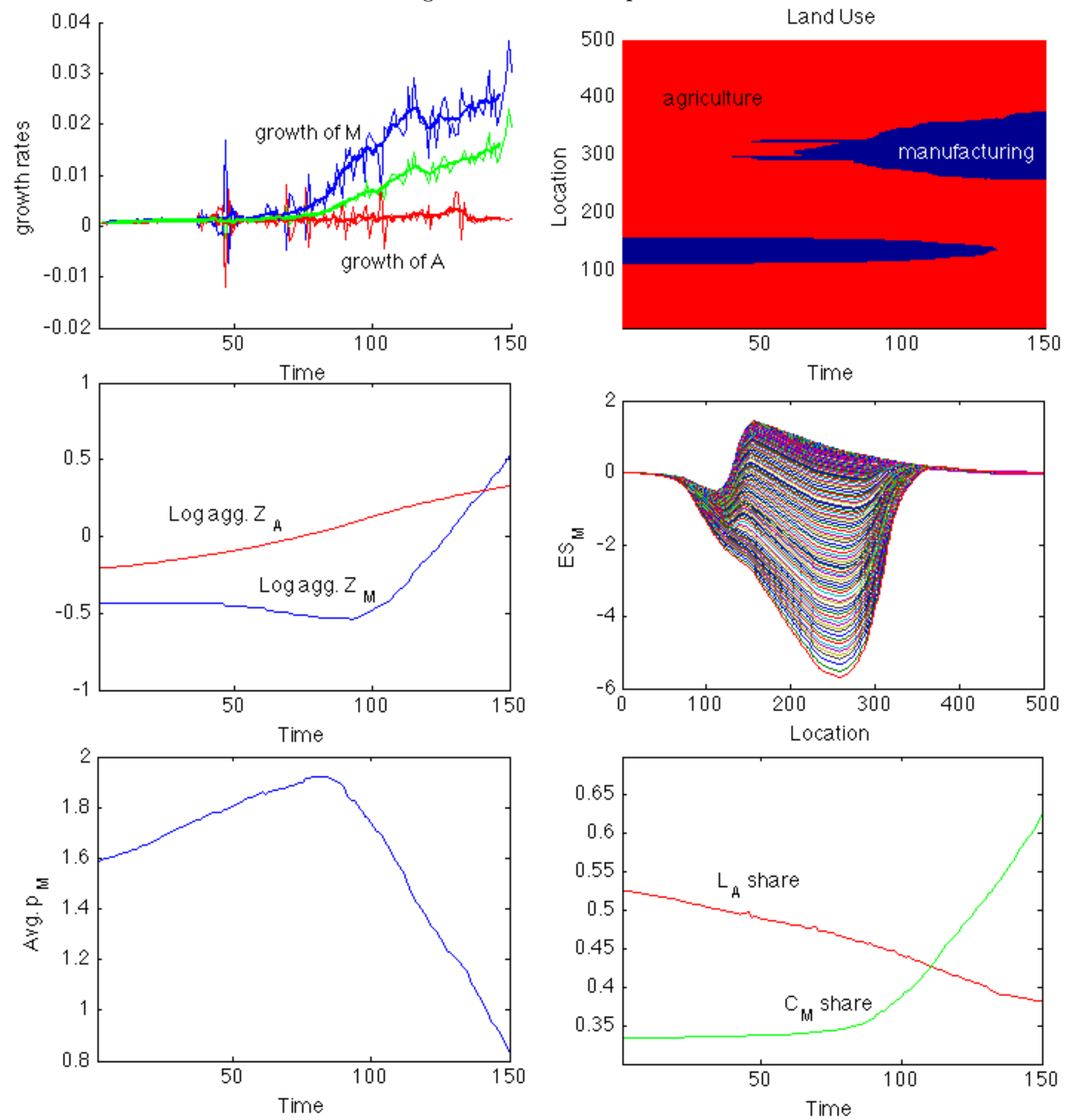
Figure 5: Model (thick) vs. Data (thin), 1710-1860
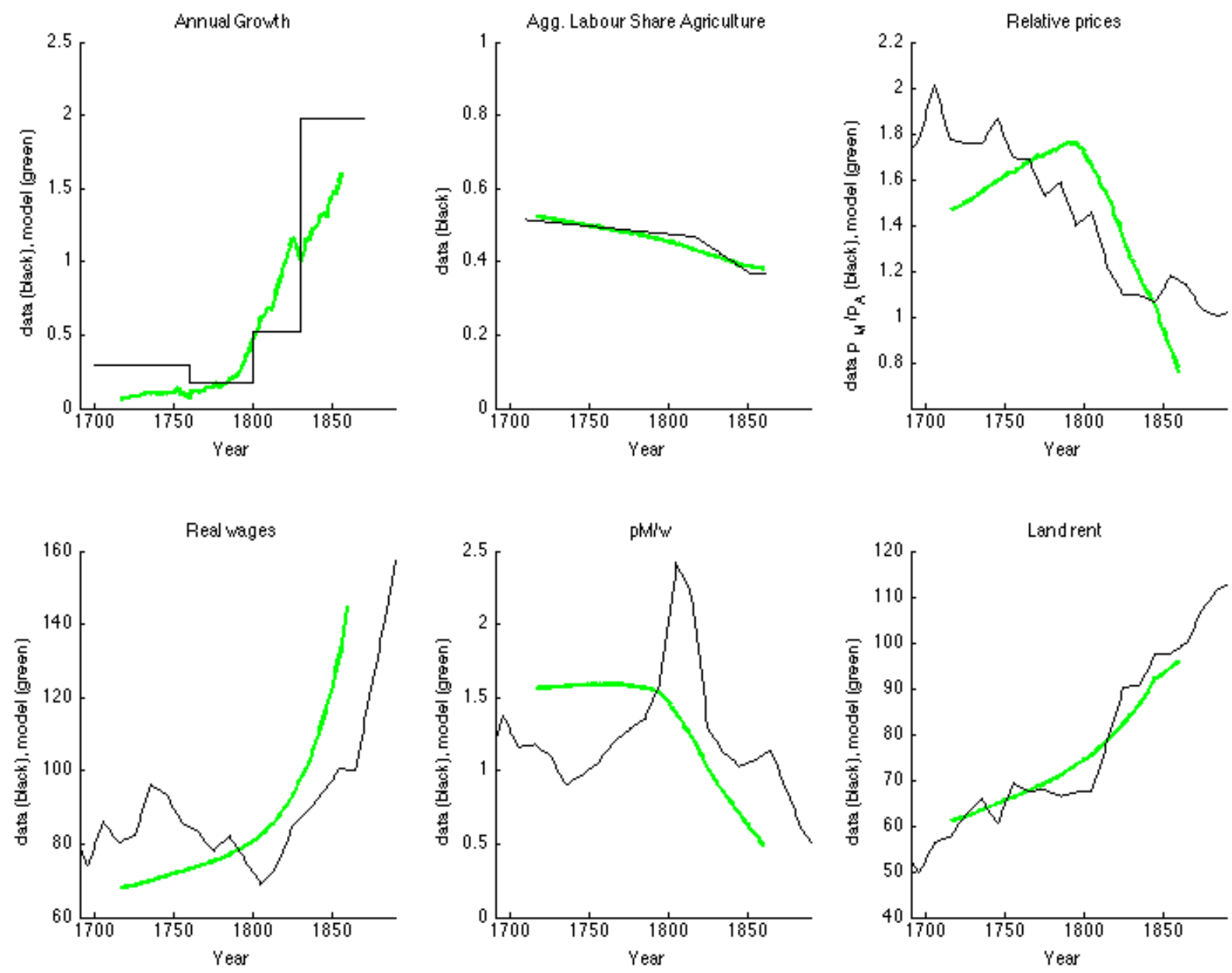
Figure 6: Model vs. primary employment at 1710, 1817 and 1861
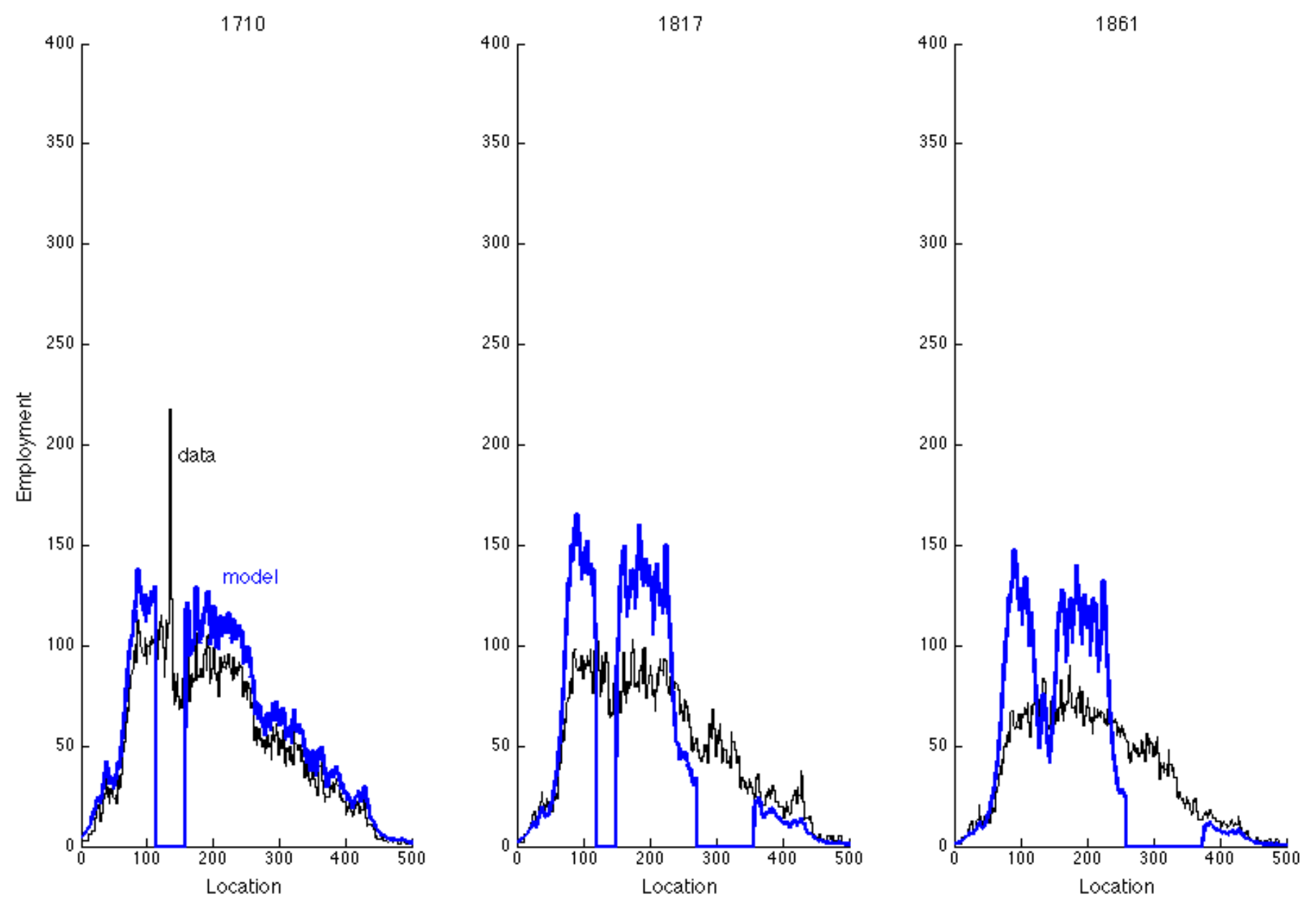
Figure 7: Model vs. secondary employment at 1710, 1817 and 1861
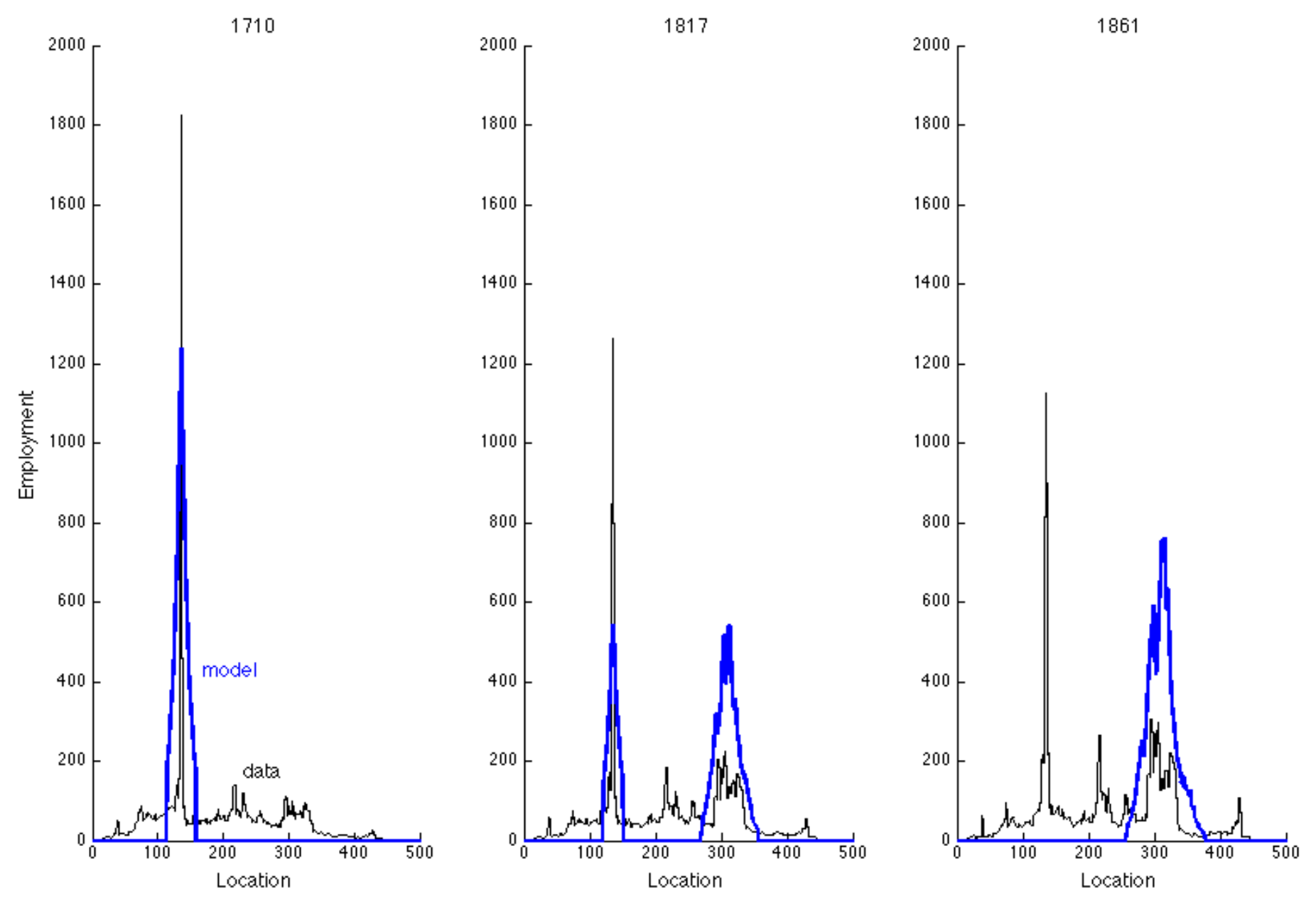
Figure 8: Model vs. textiles employment (rescaled) at 1710, 1817 and 1861
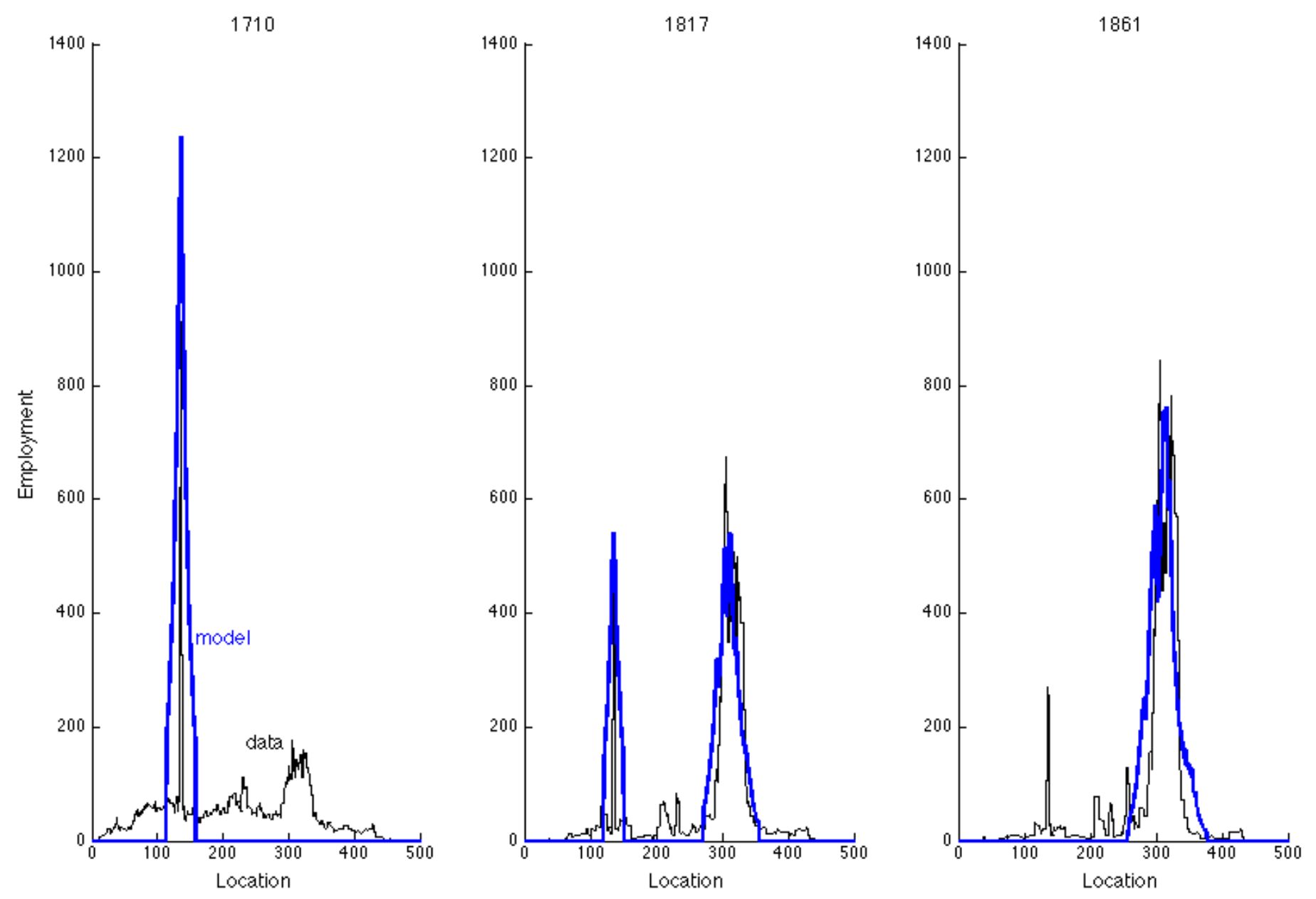
Figure 9: Alternative Initial Manufacturing Productivity Distributions
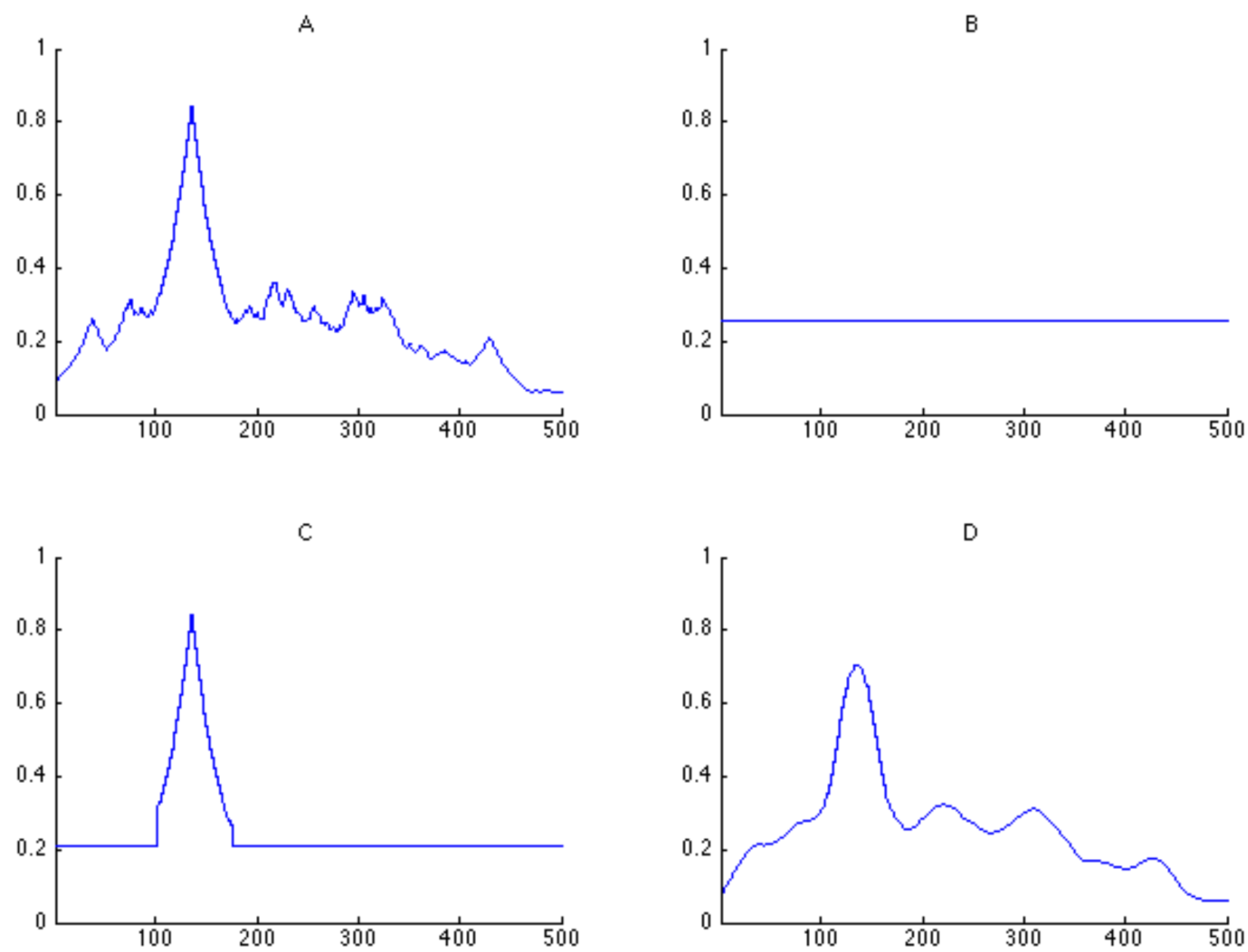